IZA DP No. 8805

The Recent Decline of Single Quarter Jobs

Henry R. Hyatt

James R. Spletzer

January 2015

Forschungsinstitut

zur Zukunft der Arbeit

Institute for the Study

of Labor 


\title{
The Recent Decline of Single Quarter Jobs
}

\author{
Henry R. Hyatt \\ CES, U.S. Census Bureau \\ and IZA \\ James R. Spletzer \\ CES, U.S. Census Bureau \\ and IZA
Discussion Paper No. 8805
January 2015 \\ IZA
P.O. Box 7240
53072 Bonn
Germany \\ Phone: +49-228-3894-0 \\ Fax: +49-228-3894-180 \\ E-mail: iza@iza.org
}

\begin{abstract}
Any opinions expressed here are those of the author(s) and not those of IZA. Research published in this series may include views on policy, but the institute itself takes no institutional policy positions. The IZA research network is committed to the IZA Guiding Principles of Research Integrity.

The Institute for the Study of Labor (IZA) in Bonn is a local and virtual international research center and a place of communication between science, politics and business. IZA is an independent nonprofit organization supported by Deutsche Post Foundation. The center is associated with the University of Bonn and offers a stimulating research environment through its international network, workshops and conferences, data service, project support, research visits and doctoral program. IZA engages in (i) original and internationally competitive research in all fields of labor economics, (ii) development of policy concepts, and (iii) dissemination of research results and concepts to the interested public.
\end{abstract}

IZA Discussion Papers often represent preliminary work and are circulated to encourage discussion. Citation of such a paper should account for its provisional character. A revised version may be available directly from the author. 


\section{ABSTRACT}

\section{The Recent Decline of Single Quarter Jobs*}

Rates of hiring and job separation fell by as much as a third in the U.S. between the late 1990 s and the early 2010s. Half of this decline is associated with the declining incidence of jobs that start and end in the same calendar quarter, employment events that we call "single quarter jobs." We investigate this unique subset of jobs and its decline using matched employer-employee data for the years 1996-2012. We characterize the worker demographics and employer characteristics of single quarter jobs, and demonstrate that changes over time in workforce and employer composition explain little of the decline in these jobs. We find that the decline in these jobs accounts for about a third of the decline in the fraction of the population that holds a job in the private sector that occurred from the mid -2000s to the early 2010s. We also find little evidence that single quarter jobs are stepping stones into longerterm employment. Finally, we show that the inclusion or exclusion of these single quarter jobs creates divergent trends in average earnings and the dispersion of earnings for the years 1996-2012. To the extent that administrative records measure the volatile tail of the employment distribution better than conventional household surveys, these findings show that measurement of short duration jobs matters for economic analysis.

JEL Classification: J21

Keywords: $\quad$ hires, separations, single quarter jobs, stepping stone jobs

Corresponding author:

James R. Spletzer

Center for Economic Studies

U.S. Census Bureau

4600 Silver Hill Road

Washington, DC 20233

USA

E-mail: James.R.Spletzer@census.gov

\footnotetext{
* Any opinions and conclusions expressed herein are those of the authors and do not necessarily represent the views of the U.S. Census Bureau. All results have been reviewed to ensure that no confidential information is disclosed. We thank Lucia Foster, John Haltiwanger, Hubert Janicki, Leo Sveikauskas, and participants at the 2014 SoLE and 2015 ASSA conferences for helpful comments and suggestions.
} 


\section{Introduction}

The rate at which workers and jobs move across employers in the U.S. has been declining during the last several decades: see, for example, Hyatt and Spletzer (2013), Decker et.al. (2014), and Davis and Haltiwanger (2014). From the mid-to-late 1990s - the start of most time-series statistics of hires, separations, job creation, job destruction, and job-to-job flows - to the early 2010s, these measures have declined by a fourth to a half. Policy makers have begun thinking of declines in employment dynamics as a possible measure of slack in the labor market. ${ }^{1}$ Nevertheless, the reasons for these declines remain largely unknown.

In this paper, we address one aspect of this decline: the dramatic decline of single quarter jobs in the U.S. from 1996 to 2012. Single quarter jobs are defined as those jobs that begin and end within the same calendar quarter. Hyatt and Spletzer (2013) show that the incidence of single quarter jobs fell from 11.4 percent in the late 1990 s to 6.0 percent in the early $2010 \mathrm{~s}$, and this decline explains over half of the decline in total hires and separations. Our goals in this paper are to document the characteristics of these single quarter jobs, and to attempt to shed some light on some of the causes and consequences of this recent decline.

Not much is known about single quarter jobs. There are a number of reasons to believe that these and other relatively short duration jobs serve an essential function in the labor market. For example, basic learning models have individuals and firms trying out new matches in an environment of incomplete information. Bad matches may reveal themselves quite quickly, and as such it is not surprising to see a significant number of short duration jobs. This suggests that the declines in single quarter jobs might reflect better initial match quality. But there are also competing explanations for the declines in single quarter jobs - changing composition of the workforce and of employers, seasonality may be diminishing over time, or secular transformations in the production process might lead to changing factor ratios of short duration and longer duration jobs.

\footnotetext{
${ }^{1}$ See Yellen (2014) and Furman (2014) for further discussion.
} 
In our analysis of single quarter jobs, we pay particular attention to these various explanations, but similar to the rest of the declining dynamics literature, we are not able to find one or several dominant explanations for the decline in single quarter jobs. We make considerably more progress in documenting the consequences of this decline, which we explore in the dimensions of employment and earnings. The decline of single quarter jobs comes in the context of a broader decline in the fraction of the population that holds a private sector job in the U.S., but the decline of single quarter jobs only accounts for about a third of this broader decline. We also document that there is little evidence that single quarter jobs are "stepping stones" into more stable employment. Short duration jobs are associated with low wage and salary earnings, even when aggregated at the person-level, and the treatment of these jobs can determine the direction of the trend in the average of earnings and its variance.

We begin this paper with a description of the Longitudinal Employer-Household Dynamics (LEHD) data and a descriptive analysis of single quarter jobs. There are clear patterns in the descriptive statistics: single quarter jobs are more likely to be held by young adults, and are more likely to occur in young and small firms. However, these differences are not able to explain much of the decline in single quarter jobs in a formal decomposition. For example, the U.S. workforce has been aging recently as the baby boom approaches retirement age and the labor force participation of young adults is declining, but this compositional change towards older persons - individuals less likely to hold single quarter jobs - only explains about 10 percent of the decline of single quarter jobs.

We then turn to an analysis of the implications of single quarter jobs on employment and earnings. We aggregate our data to the person level, and begin by comparing the trend in single quarter jobs with the trend in overall employment. We find that the decline in single quarter jobs accounts for about $30 \%$ of the decline in the ratio of private-sector wage and salary employment to the U.S. population. The decline of single quarter jobs is not accompanied by individuals substituting long duration jobs for short duration jobs, but is merely part of an overall decline in jobs of both short and long durations. 
To provide a framework that accounts for other possible consequences of the decline in single quarter jobs, we analyze whether single quarter jobs are "stepping stones" that allow individuals to move into longer duration and presumably higher paying jobs. Our framework is an extension of Shimer's (2012) analysis of stocks and flows in the labor market. We find some but not much evidence for this stepping stone aspect of single quarter jobs. This is because very few people transition from nonemployment to long duration jobs with a short duration job between these two labor market states. Singe quarter jobs that are not multiple job holding are primarily a short deviation from an otherwise longer nonemployment spell.

We conclude this article by noting that the decline in single quarter jobs plays a role in understanding the trend of earnings and its dispersion in the U.S. Real earnings growth in the U.S. has been essentially nonexistent during the past decade, and earnings dispersion has been rising for several decades. Our analysis shows that the declining incidence of short duration jobs is an important factor in these trends. The magnitude and indeed the sign of these earnings trends depend on whether single quarter jobs are included in the analysis. This is because individuals who are employed only in short-duration jobs are primarily on the margins of nonemployment, and including these workers brings in a volatile tail of the earnings distribution that is in scope for computing average earnings but is often not accounted for when analyzing earnings dispersion.

We then conclude the paper with a discussion of measurement issues and suggestions about the direction of future research. Measurement matters. Our focus on single quarter jobs originated from trying to understand differences in hiring rates between administrative records such as the LEHD and household surveys such as the Current Population Survey (CPS). In our earlier paper (Hyatt and Spletzer, 2013), we hypothesized that much of the differential decline between the CPS rates and the LEHD rates is attributable to different concepts in the two data sources - not only different concepts such as main job versus all jobs, but also single quarter jobs that are likely not fully measured in the CPS. Specifically, short duration jobs may legitimately not occur during the survey's reference week, or may not be reported. To the extent that administrative records better measure the "volatile tail" of the employment distribution, this difference matters for measurement of labor market statistics such as employment, earnings, 
earnings dispersion, and tenure. We believe that our analysis in this paper has broader lessons as administrative records sources become increasingly integrated into labor market statistics and economic research.

\section{Single Quarter Jobs in the LEHD Data}

\section{IIa. The LEHD Data}

The LEHD is a longitudinally linked employer-employee dataset created by the U.S. Census Bureau as part of the Local Employment Dynamics federal-state partnership. The data are derived from state-submitted Unemployment Insurance (UI) wage records and the Quarterly Census of Employment and Wages (QCEW) data. Every quarter, employers who are subject to state Unemployment Insurance laws -- approximately $98 \%$ of all private sector employers, plus state and local governments -- submit to the states information on their workers (the wage records, which lists the quarterly earnings of every individual in the firm) and their workplaces (the QCEW, which provides information on the industry and location of each establishment). The wage records and the QCEW data submitted by the states to the U.S. Census Bureau are enhanced with census and survey microdata in order to incorporate information about worker demographics (age, gender, race and ethnicity, and education) and the firm (firm age and firm size).

Abowd et al. (2009) provide a thorough description of the source data and the methodology underlying the LEHD data and one of its main public use data products, the Quarterly Workforce Indicators (QWI). The QWI data products published by the LEHD program at the U.S. Census Bureau are available at http://lehd.ces.census.gov, and include tabulations of economic indicators such as employment, earnings, hires, separations, job creation, and job destruction by geographies, by firm characteristics, and by individual characteristics. Because states have joined the LEHD program at different times, and have provided various amounts of historical data upon joining the LEHD program, the length of the 
time series of LEHD data varies by state. All of the analysis in this paper uses private sector data from 20 states that have data available from 1996:Q1 through 2012:Q3. ${ }^{2}$

\section{IIb. Single Quarter Jobs in the LEHD Data}

Single quarter jobs are defined as employer-employee relationships that begin and end in the same calendar quarter. ${ }^{3}$ Figure 1 shows the seasonally adjusted quarterly time series of hires, separations, and single quarter jobs. On average, during the 1996 to 2012 time period, single quarter jobs account for roughly one-third of total hires and separations. This highlights the dynamism of new employer-employee matches: at least one-third of new hires remain in the firm for less than 13 weeks. Although we lack evidence on the number of days worked within the quarter, this is consistent with Robert Hall's (1995) saying about very short jobs, often quoted as "the modal job lasts 1 day."

As seen in Figure 1, the incidence of single quarter jobs falls from 8.3 percent in 1996:Q2 to 5.2 percent in $2012: \mathrm{Q} 2{ }^{4}$ Similar to the decline in the total hires and separations rates, the declining single quarter jobs rate shows a stair-step pattern where almost all of the declines are concentrated during the recessions of 2001 and 2007-2009. This is similar to declines in the broad range of employment dynamics measures documented by Hyatt and Spletzer (2013). The ratio of single quarter jobs to total hires also exhibits a stair-step pattern, falling from 38 percent in the late 1990 s, to 35 percent in the mid 2000s, to 32 percent in the early 2010 s.

\footnotetext{
2 These 20 states are: CA, CO, CT, HI, ID, IL, KS, LA, MD, MN, MO, MT, NC, NJ, NM, OR, RI, TX, WA, and WY. These 20 states account for roughly 46 percent of national employment. Using published BLS data for total private sector seasonally adjusted employment, the 1996-2012 time series from these 20 states closely tracks the national time series; the correlation between these two is .988 .

3 Two comments regarding this definition warrant mention. First, job spells that span two consecutive quarters can be less than 13 weeks duration. These are excluded from our count of single quarter jobs, and thus our estimates of single quarter jobs should be considered an underestimate of the number of jobs that last less than 13 weeks. Second, we do not consider whether these jobs are "recalls" to employers held previously, or whether workers in these jobs are subsequently recalled. For example, workers can have a seasonal job at the same employer during the same quarter every year and regard this as a long-term relationship. Our definition classifies any seasonal jobs that start and end in the same calendar quarter as single quarter jobs.

4 The hires rate, separations rate, and the single quarter job rate in Figure 1 are smaller than the published LEHD QWI rates used by Hyatt and Spletzer (2013) and cited in the introduction. The difference results from different denominators. Hyatt and Spletzer (2013) follow Abowd and Vilhuber (2011), who use the average of "beginning of quarter" and "end of quarter" employment, which is meant to measure point-in-time employment. In this paper, we use the total number of jobs during the quarter in the denominator in order to facilitate the transition to worker-level tabulations used later in this paper. Although different denominators lead to different levels of the rates, the trends are the same (the correlation between the published data and the data in Figure 1 all exceed .99).
} 
The importance of the decline in single quarter jobs for understanding the decline in total hires and separations is obvious in Figure 1. The total hires rate in Figure 1 is the sum of the hires rate into single quarter jobs plus the hires rate into jobs that last two or more quarters. Over the 1996:Q2 to 2012:Q2 time period, the total hires rate fell by 5.8 percentage points, from 22.0 percent to 16.2 percent. More than half of this decline (54.2 percent) is due to the decline in single quarter jobs; the other 45.8 percent of the decline is due to a decline in hires into jobs that will last for two or more quarters. Similarly, the total separations rate in Figure 1 is the sum of the separations rate from single quarter jobs plus the separations rate from jobs that last two or more quarters. 59 percent of the decline in total separations is attributable to the decline in single quarter jobs.

\section{IIc. Descriptive Statistics}

Table la presents descriptive statistics of single quarter jobs by worker characteristics, and Table $1 \mathrm{~b}$ presents descriptive statistics by employer characteristics. We see in Table 1a that teenagers have the highest incidence of single quarter jobs: 15.4 percent of jobs held by teenagers in any given quarter are single quarter jobs. This incidence of single quarter jobs is declining in worker age (for prime aged workers) to the point where 4.0 percent of jobs held by 55-64 year olds are single quarter jobs. The statistics in Table 1a also highlight that although teenagers are a small share of the workforce (6.0 percent of all jobs in the 20 -state LEHD data are held by teenagers), 13.2 percent of single quarter jobs are held by teenagers. One fourth (23.7 percent) of single quarter jobs are held by 25-34 year old workers. We also see that individuals with less than a high school education are also more likely to hold single quarter jobs. The main conclusions from Table 1a are that certain demographic groups are more likely to hold single quarter jobs, yet single quarter jobs are held by all types of workers.

The descriptive statistics in Table $1 \mathrm{~b}$ show that single quarter jobs are more likely in small firms and in young firms. With regard to industry composition, single quarter jobs are more likely in agriculture, construction, administrative and support and waste management, and 
accommodation and food services. ${ }^{5}$ It is not surprising to see these industries listed, since many of these are well known as high-turnover (and low-wage) industries.

The question that follows immediately from these descriptive statistics is whether compositional changes in worker and employer characteristics during the 1996-2012 time period can explain some if not all of the decline in single quarter jobs. The compositional changes that have occurred during the recent two decades suggest that this is likely: the baby boom has aged and youth labor force participation has declined, the workforce has become more educated, the share of workers at small businesses has declined, and the share of workers at young businesses has declined. Each of these shifts the composition of the employed towards sub-populations that have a lower incidence of single quarter jobs.

We measure the effect of composition changes using standard decomposition techniques. Let $\mathrm{Y}_{\mathrm{t}}$ be the incidence of single quarter jobs in quarter $t . \mathrm{Y}_{\mathrm{t}}$ can be written as $\Sigma_{\mathrm{i}} \mathrm{Y}_{\mathrm{it}} \mathrm{S}_{\mathrm{it}}$, where $\mathrm{i}$ indexes characteristics of worker or firms (such as worker age or firm size), and $\mathrm{S}_{\mathrm{i}}$ is the share of the group. We decompose the difference $\Delta \mathrm{Y}_{\mathrm{t}}=\mathrm{Y}_{\mathrm{t}}-\mathrm{Y}_{\mathrm{t}-\mathrm{x}}$ according to

$$
\Delta \mathrm{Y}_{\mathrm{t}}=\Sigma_{\mathrm{i}} \Delta \mathrm{Y}_{\mathrm{it}} \mathrm{S}_{\mathrm{i}} \cdot+\Sigma_{\mathrm{i}} \mathrm{Y}_{\mathrm{i}} \cdot \Delta \mathrm{S}_{\mathrm{it}}
$$

where $\mathrm{Y}_{\mathrm{i}}$. denotes the mean such that $\mathrm{Y}_{\mathrm{i} \bullet}=\left(\mathrm{Y}_{\mathrm{it}}+\mathrm{Y}_{\mathrm{it}-\mathrm{x}}\right) / 2$, and likewise $\mathrm{S}_{\mathrm{i} \text {. }}$ In Table 2, we report

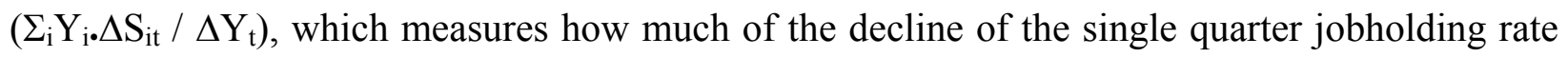
over the time period 1996:Q2 to 2012:Q2 is due to the changing composition of characteristic "i".

We see in Table 2 that no single characteristic can explain much of the decline in single quarter jobs. Worker age and firm age are the two best explanatory variables, but the aging of the workforce only explains 13.9 percent of the decline in the incidence of single quarter jobs, and the shift towards older businesses explains just 14.7 percent of the decline. Changing

\footnotetext{
5 The Administrative and Support and Waste Management industry comprises establishments performing routine support activities for the day-to-day operations of other organizations. Activities performed include: office administration, hiring and placing of personnel, document preparation and similar clerical services, solicitation, collection, security and surveillance services, cleaning, and waste disposal services.
} 
composition of other worker and employer characteristics explain essentially none of the decline. Of note, shifting industry composition shows a negative effect, as the economy shifts away from manufacturing, where there are few single quarter jobs, to services, which has higher than average rates of single quarter job holding. When we account for all worker and employer characteristics, we can only explain 21.6 percent of the decline in single quarter jobs. This implies that the decline in single quarter jobs is mostly a "within" phenomena - most of the decline occurs within sub-populations identified by demographic and employer characteristics.

We end this section with a brief discussion of seasonality. The incidence of single quarter jobs is quite seasonal -- as a percentage of all jobs, the lowest proportion occurs in the first quarter, and the highest proportion occurs in the third and fourth quarters. In the late 1990s, approximately 7.2 percent of all jobs in the first quarter are single quarter jobs, whereas roughly 9.2 percent of all jobs in the third and fourth quarters are single quarter jobs (the statistic for the second quarter is 8.2 percent). These relative proportions remain essentially the same in the early 2010s. The time series graphs of each quarter separately are presented in Figure 2. We see that the seasonal properties remain essentially the same across time while the propensity to hold single quarter jobs decreases in all quarters.

\section{Implications of the Decline for Employment}

The remaining analysis in the paper uses individual-level microdata rather than jobs-level microdata. We show in Figure 3 that this transformation makes no difference to the basic levels and trends. This figure contains two lines with different numerators and denominators. The percent of jobs series is the same as in Figure 1, and is the count of all short-duration jobs divided by the total number of jobs in the quarter. The percent of individuals series is the count of all workers with short-duration jobs divided by the number of workers employed in the quarter. $^{6}$ The incidence of jobs that are single quarter jobs falls by 37.3 percent during the

\footnotetext{
6 Implicit in the transformation from jobs-level data to individual-level data is the question of how many single quarter jobs a person holds in a given quarter. We find that the percentage of persons who hold more than one single quarter job in a quarter, conditional on holding at least one, falls from 11.6 percent in the late 1990s to 7.6 percent during the early 2010s. The time series of this decrease resembles the "stair-step" decline evident in Figures 1,2 , and 3 .
} 
1996:Q2 to 2012:Q2 time period, from 8.3 percent to 5.2 percent The percent of workers who hold a single quarter job falls by 37.6 percent, from 8.5 percent to 5.3 percent.

\section{IIIa. Substitution From Single Quarter to Multi Quarter Jobs?}

When thinking about how single quarter jobs are related to multi quarter jobs (jobs that last more than one quarter), our analysis of the data reveals that there are two "types" of persons who hold single quarter jobs. There are individuals who hold one or more single quarter jobs in a quarter without simultaneously holding a multi quarter job, and there are individuals who simultaneously hold both a single quarter job and a multi quarter job. The time series of these two types are shown in Figure 4. Both types exist, with roughly equal magnitude in the late 1990s, and both types are declining over time with the familiar "stair-step" pattern.

The decline of single quarter jobs leads us to ask whether individuals are substituting multi quarter jobs for single quarter jobs. Such a substitution could occur if matching efficiency has improved during the last two decades, could occur for simple composition reasons, or may reflect changing preferences or production processes over the last two decades. Figure 5 shows the time series of individuals who hold single quarter jobs (on the left axis) and the time series of individuals who hold only multi quarter jobs (on the right axis). The statistics in Figure 5 are percentages of the total population, so the three lines add to the ratio of private sector employment divided by the U.S. population. ${ }^{7}$ The decline of single quarter jobs is accompanied by a simultaneous and much larger trend decline in individuals with only multi quarter jobs. This implies that the decline in single quarter jobs is not easily explained as a switch of persons from single quarter jobs to multi quarter jobs. Furthermore, as a hint of results to come, note that the decline in single quarter jobs plays only a small role in explaining the recent decline in the employment-to-population ratio that occurred pre and post the 2007-2009 recession. A back-ofthe envelope comparison, made by comparing the total change to its components, suggests that

\footnotetext{
${ }^{7}$ Two technical notes warrant mentioning. First, population data is annual state level data from the Census Bureau's website, linearly interpolated across quarters within the year. Second, the employment-to-population ratio of roughly 50 percent in the LEHD data may seem low relative to published statistics from the U.S. Bureau of Labor Statistics, but recall that we excluded government jobs and the LEHD does not measure the self-employed.
} 
the decline of single quarter jobs would explain about $30 \%$ of the decline in employment-topopulation rate from the mid 2000 s to the early 2010 s.

\section{IIIb. Transition Rates into and from Single Quarter Jobs}

Are single quarter jobs stepping stones to multi quarter and presumably higher paying jobs? Various economic theories would suggest that this is so. For example, theories of career ladders imply that individuals begin on the bottom rung in low-paying entry level jobs, accumulate labor market experience, and move up to higher-paying rungs as quickly as possible. The basic description of jobs on the bottom rungs would include low-paying low-tenure (i.e. single quarter) jobs. There is plenty of empirical evidence that the first jobs of labor market entrants are of relatively short duration; see, for example, Topel and Ward (1992). Of course not all single quarter jobs are entry level jobs - Figure 4 suggests that about half of all single quarter jobs are multiple jobholding. But in the likely scenario that many of the single quarter jobs without an accompanying multi quarter job are entry level jobs, the decline in these jobs is worrisome regarding the ability of youth and other new entrants to get a foothold on the bottom rungs of the career ladder.

We look directly at employment dynamics and ask whether single quarter jobs held today enable transitions into multi quarter jobs. We then estimate a steady-state model of labor market transitions and ask the counterfactual question of what would have happened if single quarter jobs had not declined. Specifically, has the decline in single quarter jobs decreased the number

of multi quarter jobs, with a corresponding increase in the number of nonemployed individuals? In order to estimate such counterfactual questions, we use the steady state methods of stocks and flows pioneered by Shimer (2012).

Our analysis considers a job's duration to be a time-invariant job characteristic. This simplifying assumption is powerful in that it allows us to describe holding jobs of particular durations as an employment state, and allows us to apply standard stock-flow analysis to this problem. The natural tradeoff here is that we only consider contemporaneous movements between single quarter and longer duration jobs. We could have allowed the holding of a single 
quarter job to have longer-lasting implications, but this comes at the cost of having steady-state equations that rapidly increase in complexity. Nevertheless, the four states defined by the contemporaneous interactions between single quarter jobs and multi quarter jobs is a natural starting point for our transition analysis.

In our application, individuals can be in one of four labor market states during any quarter: "None" represents individuals with no single quarter jobs and no multi quarter jobs, "Multi" represents individuals with no single quarter jobs and one or more multi quarter jobs, "Single" represents individuals with one or more single quarter jobs and no multi quarter jobs, and "Both" represents individuals with one or more single quarter jobs and one or more multi quarter jobs. $^{8}$ All the empirical work in this section uses data restricted to individuals aged 18 65 (the conventional working age population).

We begin with a presentation of the underlying stocks and flows matrix. Table 3a presents the 4-by-4 matrix, where the statistics in each cell reflect population percentages (the data in Table 3 are pooled over all quarters 1996:Q2 to 2012:Q2). The transition probability matrix, which is derived from the stocks and flows matrix, is presented in Table $3 \mathrm{~b}$. Looking first at the margins of table $3 \mathrm{a}$, we see that roughly 52.5 percent of individuals are employed in just multi quarter jobs in the average quarter, and 43.7 percent are nonemployed in the average quarter. Recall that government jobs and the self-employed are not in the LEHD dataset and as such individuals holding these types of jobs are classified here as nonemployed.

In Table 3b, looking at persons who are initially nonemployed, many more go directly to multi quarter jobs (7.4 percent) than to single quarter jobs (3.4 percent), with a negligible proportion moving to both a single quarter and a multi quarter job. Of those persons who hold one or more single quarter jobs and no longer duration job, only 18.6 percent $(15.2+3.4)$ move on to multi quarter jobs, whereas 69.0 percent move to nonemployment. These statistics imply that most persons who transition from nonemployment to a single quarter job go back to

\footnotetext{
8 We started our analysis with nine labor market states, defined by the various combinations of $\{0,1,2+\}$ single quarter and multi quarter jobs. The resulting 9-by-9 transition matrix contained quite a few sparsely populated cells. We experimented with several aggregations and believe the four labor market states defined by the various combinations of $\{0,1+\}$ single quarter and multi quarter jobs balances the competing interests of preserving the heterogeneity across individuals with an estimable steady state.
} 
nonemployment the following quarter. There is little evidence in Tables $3 a$ and $3 b$ that single quarter jobs are the first rung of the career ladder that enable the nonemployed to transition to longer duration jobs on higher rungs of the ladder.

Much of the stepping stone literature looks at youth and young adults. As such, we repeat the transition analysis for persons aged 18 to 24 (rather than the 18 to 65 in Tables $3 a$ and $3 b)$. The transition matrix and the transition probabilities for young adults are given in Tables $4 \mathrm{a}$ and $4 \mathrm{~b}$. We see in Table $4 \mathrm{~b}$ that young adults are much more likely than all prime-age persons to leave nonemployment in any given quarter: 25.4 percent of nonemployed young adults become employed the following quarter, compared to 11.4 percent of persons aged 18-65. This should not be surprising. But regarding stepping stones, similar to the results for all prime-age persons in Table $3 \mathrm{~b}$, the results for young adults in Table $4 \mathrm{~b}$ indicate that the transition rate from nonemployment into multi quarter jobs greatly exceeds the transition rate into single quarter jobs (16.5 percent relative to 7.2 percent). Furthermore, mimicking the results in Table 3b, it appears that only a few young adults who transition from nonemployment to just a single quarter job further transition into longer duration jobs. Most young adults who hold one or more single quarter jobs without holding a multi quarter job transition into nonemployment the following quarter. We find little evidence that single quarter jobs are the first rung of the career ladder that enable young adults to successfully transition from nonemployment to longer duration jobs.

\section{IIIc. Steady State and Stepping Stones}

Even though there is little empirical evidence that single quarter jobs are stepping stones into longer duration jobs, the 4-by-4 transition matrix is still valuable in that it can provide evidence for why the incidence of single quarter jobs has been declining. The analysis that follows is based on Shimer's (2012) methodology of steady state stocks and flows, where the stocks (the margins of the transition matrix) are expressed as functions of the transition matrix's

off-diagonal flows. Shimer showed this for a 3-by-3 matrix. Our application requires extending this to a 4-by-4 matrix. A complete description of the methodology and the exact solution to the 4-by-4 matrix is given in the appendix. 
We estimate the 4-by-4 steady state for \{None, Multi, Single, Both\}, where the steady state in each quarter is defined as the estimated stocks (as a function of the off-diagonal transition rates) when each transition rate is set at its quarterly average. Mimicking Shimer (2012), it is worthwhile to compare the observed data to the estimated steady state - this is done in Figure 6. Our steady state model overpredicts nonemployment and underpredicts multi quarter jobs during the two recessions. We don't consider this a flaw, since recessions should not be considered a steady state where flows into a labor market state equal the flows out of that state (one of the key assumptions underlying the steady state model). Over the long run, the estimated steady state replicates the rising nonemployment rate. The estimated steady state also predicts just about perfectly both the level and the trend of the population percentage of the two types of individuals with single quarter jobs.

We ask which of the transition probabilities contributes the most to the declining trend of single quarter jobs. Table 5 contains 48 statistics; each of the 48 is the result of a different independent model. Each statistic is the covariance between the observed data and the estimated steady state model with all transition probabilities set to their long run (1996-2012) average with the exception of the one transition probability listed in the left column of Table 5 which is set to its seasonally adjusted quarterly average. ${ }^{9}$

Estimated explanations for the declining trend of the incidence of holding just single quarter jobs are in the third column of statistics in Table 5. The best explanation of this declining trend is the decreasing transition probability from nonemployment into these single quarter jobs. The covariance between the observed data and the steady state allowing only this one transition rate to vary over time is .822 . In contrast, the exit rate from these single quarter jobs to nonemployment explains much less of the declining trend; the covariance here is .122. Thus the declining trend of individuals who hold a single quarter job but not a multi quarter job is due to the "ins" rather than the "outs."

\footnotetext{
${ }^{9}$ It is invalid to add the statistics in each column and expect them to sum to one. This is because the transition rates are related to each other (when one increases, one other transition rate in the same row of the 4-by-4 matrix has to decrease), yet our statistical exercise treats them as independent.
} 
The declining trend of single quarter jobs for individuals who hold both a single quarter job and a multi quarter job has a different explanation. The best explanation here, with an estimated covariance of .619 (in the fourth column of Table 5), is the declining transition rate into this state for individuals who previously held just a multi quarter job. The economic interpretation is that individuals with only a multi quarter job have a declining propensity to add a second single quarter job.

The analysis in the previous two paragraphs helps us explain why single quarter jobs have been declining. Two major statistical explanations are a declining entrance rate from nonemployment and a declining propensity to add multiple jobs. But we need to be careful not to over-interpret these results -- we still don't know the driving forces for why these rates have been declining over time.

The steady state estimated from the 4-by-4 matrix is powerful beyond enabling us to examine why single quarter jobs have been declining. Column 2 of Table 5 presents estimates which allow us to analyze why the incidence of persons holding only multi quarter jobs has been declining over time. We see that the stepping stone role of single quarter jobs has only a small effect on this downward trend. Allowing the rate from nonemployment to single quarter jobs to vary yields a covariance of .078 (the second row in column 2), and allowing the rate from single quarter jobs to exclusively multi quarter jobs to vary yields a covariance of .053 . Both of these stepping stone effects are quite small. The best explanation for the decrease in multi quarter jobs is the declining entrance rate from nonemployment. Indeed, the estimated covariance above one (1.209, in the top row of column 2) reflects the over-prediction evidenced in Figure 6 that occurs during recessions.

And finally, the estimated steady state model allows us to analyze the rising nonemployment rate, which is equivalent to a falling employment to population ratio. The best explanation for the rising nonemployment rate in our LEHD data is a falling entrance rate from nonemployment to any type of employment - see the top three rows of the first column of Table 5. While the entrance rate into the two types of single quarter jobs has a smaller effect than the entrance rate into multi quarter jobs, the single quarter job effects are non-negligible. 


\section{Implications of the Decline for Earnings}

We now turn to the relationship between the declining incidence of single quarter jobs and the trends in average earnings and earnings dispersion. Both of these earnings trends have been the focus of recent attention in the U.S. By almost all measures, earnings growth has stagnated during the past decade and earnings inequality has been increasing during the past several decades.

Two approaches are generally taken when using employment and earnings data in economic research. The broadest approach is to let the universe of records constitute the object of consideration. This approach is commonly used in the production of economic statistics, such as employment counts or average earnings. This is sometimes referred to as a "business based" approach, as it considers the people employed by all businesses at any point in time. An alternative approach restricts the universe on some measure of the individual's job attachment. For example, the inequality statistics produced by the Bureau of Labor Statistics restrict on fulltime workers when tabulating earnings data from the Current Population Survey (CPS). ${ }^{10}$ In this section, we show that the basic distinction between these approaches - the inclusion or exclusion of what might be deemed marginal jobs - has a noticeable effect on the trend of average earnings and a substantial effect on the trend of earnings dispersion.

We begin by presenting the seasonally adjusted time series of the number of individuals in our 20 state LEHD dataset. Figure 7 shows the number of individuals with full quarter jobs, and the number of individuals with full quarter and/or single quarter jobs. ${ }^{11}$ Full quarter jobs are defined as contemporaneous employer-employee matches that existed in the previous quarter and also exist in the following quarter. Full quarter jobs basically ensure that the individual-

\footnotetext{
${ }^{10}$ The Bureau of Labor Statistics publishes statistics for the $10^{\text {th }}, 25^{\text {th }}, 50^{\text {th }}, 75^{\text {th }}$, and $90^{\text {th }}$ percentiles of the weekly earnings distribution of full time wage and salary workers at http://www.bls.gov/webapps/legacy/cpswktab5.htm. Note that these statistics refer only to earnings at the individual's main (full time) job and exclude any earnings from multiple jobs.

${ }^{11}$ Missing from this taxonomy are jobs that begin or end within the current quarter and are at least two quarters in duration. Including these as a separate category clutters the graphs but does not change the conclusions in this section (results are available upon request). Furthermore, if we repeat all the analysis in this section using jobs rather than individuals as the unit of analysis, the conclusions become even more stark.
} 
employer match lasts longer than 13 weeks, which provides a measure of job attachment when analyzing administrative earnings records. Figure 7 shows that adding single quarter jobs to the sample of full quarter jobs increases the sample size by only a small percentage. This should not be surprising given the descriptive statistics - recall from Figure 4 that individuals with only single quarter jobs are $4 \frac{1}{2}$ percent of all employed individuals in the late 1990s and 3 percent of all employed individuals in the 2010s.

\section{IVa. Trends in Average Earnings}

As shown in Figure 8, the inclusion or exclusion of single quarter jobs from the calculation of average log real quarterly earnings matters a lot. ${ }^{12}$ This is immediately obvious in the levels, but more important for our purposes is the trends. Average earnings among those who work at any job during the quarter is increasing from the late 1990s to the early 2000s, and then grows by just a small amount from the mid 2000s to the early 2010s (this is the dashed line in Figure 9). On the other hand, average earnings of full quarter jobs also rises during the late 1990s but has essentially no growth during the decade of the 2000s. Indeed, the average earnings of full quarter jobs declines during the 2007-2009 recession.

The divergent trends of average earnings in Figure 8 result from whether or not single quarter jobs are included in the calculation. The divergence is most pronounced during the 20072009 recession, where the stagnant earnings of individuals working at any job in the LEHD reflects declining earnings of individuals with full quarter jobs and an upward trend reflecting the recent decline of single quarter jobs. This latter effect is a composition effect resulting from removing a sizable percentage of low-paid jobs from the calculation of average earnings. Thus the decline in single quarter jobs matters when analyzing recent trends in average earnings.

\section{IVb. Trends in Earnings Dispersion}

The growth of earnings inequality is at the forefront of current policy discussions, and has been referred to as the defining challenge of our time. Although much of the early analysis

\footnotetext{
${ }^{12}$ In the text that follows, average earnings is shorthand for average log real quarterly earnings.
} 
of increasing inequality comes from analysis of the CPS data, there has been quite a bit of recent research using administrative earnings records - see, for example, see Piketty and Saez (2003), Saez (2013), Card, Heining, and Klein (2013), Barth, Bryson, Davis, and Freeman (2014), and Spletzer (2014).

Much of the analysis of inequality that uses household data restricts on labor supply, such as restricting to persons working more than 35 hours per week. This is not possible with administrative data, since information on hours worked is not available in most administrative earnings records. To ensure some job attachment, analysts who use LEHD data often restrict on what is called "full quarter" earnings - only the middle quarter of a worker-employer match that lasts at least three consecutive quarters is used in the analysis.

Figure 9 presents the seasonally-adjusted time series of the variance of the quarterly earnings distribution. Two series are given: earnings variance for individuals with just full quarter jobs, and earnings variance for individuals with full quarter and/or single quarter jobs. The earnings variable used to create these graphs is the natural log of real quarterly earnings. ${ }^{13}$ The variance of individual full quarter earnings rises steadily from the mid-to-late 1990s to the early 2010s. This variance rises by 12 percent, which indicates increasing earnings inequality. On the other hand, the variance of individual quarterly earnings from both full quarter jobs and single quarter jobs declines during the 1996 to 2012 time period. This decline is 7 percent. Of interest is the noticeable stair-step decline in this variance trend, which is suggestive that the decline of the incidence of single quarter jobs plays a role in this declining variance.

We dig deeper into the divergent variance trends and present various percentiles of the earnings distribution in Figure 10. The top panel of Figure 10 presents the 90-10 ratio, the 90-50 ratio, and the 50-10 ratio for the sample of individuals with full quarter jobs. The 90-10 ratio is increasing over the 1996 to 2012 time period, with a large increase in the upper part of the earnings distribution (as represented by the 90-50 ratio) and a relatively flat trend in the lower part of the earnings distribution (as represented by the 50-10 ratio). Spletzer (2014) shows that

\footnotetext{
${ }^{13}$ Because there are a few outliers, most likely due to year end bonuses or other irregular large payments, we have winsorized the earnings distribution at 99 percent of the state-year-quarter distribution. We have also smoothed over a noticeable spike in the variance at 2007:Q2.
} 
these three series are extremely similar to the corresponding statistics from the published CPS data.

The bottom panel of Figure 10 presents a different evolution of the earnings distribution in the U.S. This bottom panel presents the 90-10, 90-50, and 50-10 ratios for the sample of individuals with full quarter and/or single quarter jobs. Here, we still see a sizeable widening in the upper half of the earnings distribution, but the bottom half of the earnings distribution is narrowing. The narrowing bottom half is greater than the widening of the upper half, which leads to a declining 90-10 ratio. This declining 90-10 ratio is consistent with the corresponding declining variance in Figure 9.

Our point here is not to question the trend of increasing earnings inequality. Rather, our purpose in this section is to show that including single quarter jobs in the analysis drastically changes the trend of earnings inequality. Our analysis of full-quarter earnings replicates the trend of increasing earnings inequality documented in the literature. Not controlling for an individual's attachment to the labor market, and using the approach where all individuals are included in the analysis, reverses the trend. This is because individuals who are employed only in short-duration jobs are primarily on the margins of nonemployment, and including these workers brings in a downward trend in the variance induced by the composition effect resulting from the declining trend of low-earnings single quarter jobs. ${ }^{14}$

\section{Summary and Discussion}

We have thoroughly documented a phenomenon that commonly occurs in administrative records: events that start and end in the smallest duration available. In the case of quarterly earnings records, these are jobs that start and end in the same quarter, which we refer to as "single quarter jobs." We were motivated to analyze these jobs by the finding from Hyatt and Spletzer (2013) that the decline of single quarter jobs accounts for more than half of the decline in hires and separations in U.S. administrative records. We show in this paper that single quarter

14 Evidence suggests that administrative data are better than household data in measuring short duration low earnings jobs in the tail of the earnings distribution - see Abraham et.al. (2013). This suggests that the composition effects resulting from not restricting on labor market attachment will be larger when using administrative data. 
jobs are commonly held by younger workers and by those who take jobs at newer firms, but, nevertheless, the aging of the workforce and the decline of business startups explains relatively little of the decline in single quarter jobs. This finding is consistent with other evidence from Hyatt and Spletzer (2013), Decker et al. (2014), and Davis and Haltiwanger (2014), who also show that compositional shifts explain little of the decline in employment dynamics.

We make much more progress considering the implications of the decline in single quarter jobs on change in employment and earnings among the U.S. private sector workforce. We find that the decline of single quarter jobholding only accounts for about a third of the decline in the number of people employed in a quarter, and as such, the decline in single quarter jobs is part of a broader decline in the employment to population ratio in the U.S. We also consider whether the decline in single quarter jobs affects the broader employment decline via a stepping stone effect. We set up a simple four-state model of the labor market that follows and extends Shimer (2012), and we find some but not much explanatory power from this stepping stone channel.

While a small part of this paper, we believe that our analysis of single quarter jobs as stepping stones presents two methodological advances for the study of employment. First, most studies of stepping stone jobs, such as Booth, Francesconi, and Frank (2002), Gagliarducci (2005), and Autor and Houseman (2010), analyze the implications of temporary contract jobs (in Europe) or temporary-help jobs (in the U.S.) on future labor market outcomes such as employment and earnings. The general empirical methodology is to regress the current wage on previous stepping stone jobs, controlling for possible selectivity into employment. Our analysis, in contrast, is a simple stock-flow analysis that directly looks at the stepping stone dynamics of workers as they move into and out of nonemployment, as well as from job to job. Second, our analysis of single quarter jobs as stepping stones requires us to extend Shimer's (2012) steady state stocks and flows methodology from a 3-by-3 matrix of gross flows amongst labor force states to a 4-by-4 matrix. We believe that this extension will be useful to other analysis of labor market dynamics, such as gross flows distinguishing between remaining at the same employer versus changing jobs, distinguishing between short-duration versus long-duration unemployment, or distinguishing between discouraged workers versus out of the labor force. 
For earnings trends, the treatment of single quarter jobs matters quite a lot. One may be tempted to assume that since single quarter jobs are just a small percentage of jobs, inequality trends would not be strongly affected by their inclusion or exclusion. But this intuition is wrong. Inclusion or exclusion of single quarter jobs from average quarterly earnings or the dispersion of quarterly earnings generates divergent and even opposite trends for the years 1996-2012. Including single quarter jobs, where the total earnings are rather low, indicates that average earnings of workers in the private sector has been increasing, with declining dispersion. This is because the number of single quarter jobs is declining dramatically and the resulting composition effect dominates the trend. When omitting single quarter jobs, the remaining earnings observations from longer duration jobs show an opposite trend: average earnings has been flat or perhaps declining, with increasing dispersion.

Single quarter jobs begin and end in a short interval, and so they contribute both a hire and a separation to quarterly statistics on workforce turnover and churn. For the same reason, these short duration jobs also contribute weight toward recently started jobs in statistics on job tenure. The proper treatment of these jobs is therefore essential to the consideration of trends in employment dynamics, as well as trends in job mobility and duration. As we show in Hyatt and Spletzer (2014), single quarter jobs drive the trend in the job duration distribution in the Quarterly Workforce Indicators (QWI).

As administrative records sources increasingly come to the forefront of labor market research, it is necessary to carefully think of how to characterize employment and earnings in these data sources. The administrative earnings records that provide the source data for the LEHD are collected for the purpose of assessing unemployment insurance taxes in the U.S. Administrative earnings records exist in many other countries for purposes of tax collection and benefit provision. These data are collected or recorded at different frequencies in different countries: daily, monthly, quarterly, or annually. We hope that this paper and other pioneering efforts will help to provide a conceptual framework appropriate to these administrative data sources, and that future work will assist in the reconciliation of these data with other more established labor market data obtained from surveys. 


\section{References}

Abowd, John M., Bryce E. Stephens, Lars Vilhuber, Fredrik Andersson, Kevin L. McKinney, Marc Roemer, and Simon Woodcock. 2009. "The LEHD Infrastructure Files and the Creation of the Quarterly Workforce Indicators." In Producer Dynamics, ed. Timothy Dunne, J. Bradford Jensen, and Mark J. Roberts. Chicago, IL: University of Chicago Press.

Abowd, John M. and Lars Vilhuber. 2011. "National Estimates of Gross Employment and Job Flows from the Quarterly Workforce Indicators with Demographic and Industry Detail," Journal of Econometrics 161(1): 82-99.

Abraham, Katharine G., John Haltiwanger, Kristin Sandusky, and James R. Spletzer. 2013. "Exploring Differences in Household vs. Establishment Measures of Employment." Journal of Labor Economics 31(2, pt. 2): S129-S172.

Autor, David and Susan N. Houseman. 2010. "Do Temporary Help Jobs Improve Labor Market Outcomes for Low----Skilled Workers? Evidence from 'Work First."' American Economic Journal: Applied Economics, Volume 2 (July), 2010, 96-128.

Barth, Erling, Alex Bryson, James C, Davis, and Richard Freeman. 2014. "It's Where You Work: Increases in Earnings Dispersion Across Establishments and Individuals in the U.S." NBER Working Paper \#20447.

Booth, Alison L, Marco Francesconi, and Jeff Frank. 2002. “Temporary Jobs: Stepping Stones or Dead Ends?” The Economic Journal, Vol. 112, No. 480, pp. F189-F213.

Card, David, Jörg Heining, and Patrick Kline. 2013. "Workplace Heterogeneity and the Rise of West German Wage Inequality." The Quarterly Journal of Economics, vol. 128(3), pp. 9671015.

Davis, Steven J. and John Haltiwanger. 2014. "Labor Market Fluidity and Economic Performance." NBER Working Paper \#20479.

Decker, Ryan, John Haltiwanger, Ron S. Jarmin, and Javier Miranda. 2014. "The Secular Decline in Business Dynamism in the U.S.” Unpublished paper, U.S. Census Bureau.

Furman, Jason. 2014. "Opportunities and Challenges in the U.S. Labor Market: An Update ." http://www.whitehouse.gov/sites/default/files/docs/opportunities and challenges in the u.s. labor_market_an_update_jf_9.10.14.pdf.

Gagliarducci, Stefano. 2005. "The dynamics of repeated temporary jobs", Labour Economics, 12(4), pp. 429-448.

Hall, Robert E. 1995. "Lost Jobs.” Brookings Papers on Economic Activity. Vol. 1995, No. 1, pp. 221-273. 
Hyatt, Henry R. and James R. Spletzer. 2013. "The Recent Decline in Employment Dynamics.” IZA Journal of Labor Economics, Vol. 2, No. 5, pp. 1-21.

Hyatt, Henry R. and James R. Spletzer. 2014. "Hires, Separations, and the Job Tenure Distribution in Administrative Earnings Records." JSM Proceedings, Business and Economic Statistics Section, pp. 98-110.

Piketty, Thomas and Emmanuel Saez. 2003. "Income Inequality in the United States, 19131998.” The Quarterly Journal of Economics, vol. 118(1), pp. 1-39.

Saez, Emmanuel. 2013. "Striking it Richer: The Evolution of Top Incomes in the United States (Updated with 2012 preliminary estimates)." Manuscript, University of California Berkeley, http://elsa.berkeley.edu/users/saez/saez-UStopincomes-2012.pdf.

Shimer, Robert. 2012. "Reassessing the ins and outs of unemployment." Review of Economic Dynamics, Vol. 15, pp. 127-148.

Spletzer, James R. 2014. "Inequality Statistics from the LEHD." Presented at the June 2014 FESAC meetings, http://www.census.gov/fesac/pdf/2014-06-13/Spletzer_Background.pdf.

Topel, Robert H. and Michael P. Ward. 1992. "Job Mobility and the Careers of Young Men." Quarterly Journal of Economics 107(2): 439-479.

Yellen, Janet. 2014. "Labor Market Dynamics and Monetary Policy." http://www.federalreserve.gov/newsevents/speech/yellen20140822a.pdf. 


\section{Appendix: Shimer's Methodology and the Extension to a 4-by-4 Matrix}

In any given quarter, individuals can be in one of four labor market states: $N$ represents individuals with no single quarter jobs and no multi quarter jobs, $M$ represents individuals with no single quarter jobs and one or more multi quarter jobs, $S$ represents individuals with one or more single quarter jobs and no multi quarter jobs, and $B$ represents individuals with one or more single quarter jobs and one or more multi quarter jobs. In the text of this paper, as well as the tables and figures, $\{N, M, S, B\}$ are referred to as $\{$ None, Multi, Single, Both $\}$. We use the single letter notation in this appendix in order to not clutter the following mathematical equations. The stocks and flows matrix that follows individuals from last quarter $(t-1)$ to this quarter $(t)$ is:

Table A1: Map of Transitions

\begin{tabular}{cccccc}
\hline \hline & & \multicolumn{4}{c}{ Subsequent Quarter Labor Market State } \\
\cline { 3 - 6 } & & $N_{t}$ & $M_{t}$ & $S_{t}$ & $B_{t}$ \\
\hline Previous & $N_{t-1}$ & $N_{t-1} N_{t}$ & $N_{t-1} M_{t}$ & $N_{t-1} S_{t}$ & $N_{t-1} B_{t}$ \\
Labor & $M_{t-1}$ & $M_{t-1} N_{t}$ & $M_{t-1} M_{t}$ & $M_{t-1} S_{t}$ & $M_{t-1} B_{t}$ \\
Market & $S_{t-1}$ & $S_{t-1} N_{t}$ & $S_{t-1} M_{t}$ & $S_{t-1} S_{t}$ & $S_{t-1} B_{t}$ \\
State & $B_{t-1}$ & $B_{t-1} N_{t}$ & $B_{t-1} M_{t}$ & $B_{t-1} S_{t}$ & $B_{t-1} B_{t}$ \\
\hline
\end{tabular}

In this matrix, an individual who is not employed last quarter $\left(N_{t-1}\right)$ and is employed this quarter in a single quarter job $\left(S_{t}\right)$ would be in the $N_{t-1} S_{t}$ cell. The notation used here denotes $\{N, M, S, B\}$ as stocks (that is, counts of individuals). This stocks and flows matrix, averaged over all quarters and expressed as population percentages, is presented in Table $3 \mathrm{a}$.

Define transition probabilities across the four labor market states as $\lambda$, where, for example, $\lambda^{N S}$ is the probability of a nonemployed person in quarter $t-1$ being employed in a single quarter job in quarter $t$. These are conditional probabilities in the sense that they are dependent on the initial state: for example, $\lambda_{t}^{N N}+\lambda_{t}^{N M}+\lambda_{t}^{N S}+\lambda_{t}^{N B}=1$. This transition matrix is written as: 
Table A2: Transition Rate Notation

\begin{tabular}{cccccc}
\hline \hline & & \multicolumn{4}{c}{ Subsequent Labor Market State } \\
\cline { 3 - 6 } & & $N_{t}$ & $M_{t}$ & $S_{t}$ & $B_{t}$ \\
\hline Previous & $N_{t-1}$ & $\lambda_{t}^{N N}$ & $\lambda_{t}^{N M}$ & $\lambda_{t}^{N S}$ & $\lambda_{t}^{N B}$ \\
Labor & $M_{t-1}$ & $\lambda_{t}^{M N}$ & $\lambda_{t}^{M M}$ & $\lambda_{t}^{M S}$ & $\lambda_{t}^{M B}$ \\
Market & $S_{t-1}$ & $\lambda_{t}^{S N}$ & $\lambda_{t}^{S M}$ & $\lambda_{t}^{S S}$ & $\lambda_{t}^{S B}$ \\
State & $B_{t-1}$ & $\lambda_{t}^{B N}$ & $\lambda_{t}^{B M}$ & $\lambda_{t}^{B S}$ & $\lambda_{t}^{B B}$ \\
\hline
\end{tabular}

This transition matrix, averaged over all quarters, is presented in Table $3 \mathrm{~b}$.

Given a vector of observed moments of the workforce and population $P_{t}$ $\left\{\lambda_{t}^{N N}, \lambda_{t}^{N M}, \lambda_{t}^{N S}, \lambda_{t}^{N B}, \lambda_{t}^{M N}, \lambda_{t}^{M M}, \lambda_{t}^{M S}, \lambda_{t}^{M B}, \lambda_{t}^{S N}, \lambda_{t}^{S M}, \lambda_{t}^{S S}, \lambda_{t}^{S B}, \lambda_{t}^{B N}, \lambda_{t}^{B M}, \lambda_{t}^{B S}, \lambda_{t}^{B B}, P_{t}\right\}$, we can obtain a steady-state allocation $\left\{N_{t}^{*}, M_{t}^{*}, S_{t}^{*}, B_{t}^{*}\right\}$ as follows. In a steady state, nonemployment $N$ in quarter $t-1$ equals nonemployment in quarter $t$, single quarter job holding $S$ in quarter $t-1$ equals single quarter job holding in quarter $t$, and similarly for the other two labor market states $M$ and $B$. Since the stocks are equal across time, the flows into any one of these labor market states must equal the flows out of that state. These flow equations can be written as:

$$
\begin{aligned}
& \lambda_{t}^{N M} * M+\lambda_{t}^{S N} * S+\lambda_{t}^{B N} * B=\lambda_{t}^{N M} * N+\lambda_{t}^{N S} * N+\lambda_{t}^{N B} * N \\
& \lambda_{t}^{N M} * N+\lambda_{t}^{S M} * S+\lambda_{t}^{B M} * B=\lambda_{t}^{M N} * M+\lambda_{t}^{M S} * M+\lambda_{t}^{M B} * M \\
& \lambda_{t}^{N S} * N+\lambda_{t}^{M S} * M+\lambda_{t}^{B S} * B=\lambda_{t}^{S N} * S+\lambda_{t}^{S M} * S+\lambda_{t}^{S B} * S \\
& \lambda_{t}^{N B} * N+\lambda_{t}^{M B} * M+\lambda_{t}^{S B} * S=\lambda_{t}^{B N} * B+\lambda_{t}^{B M} * B+\lambda_{t}^{B S} * B
\end{aligned}
$$

We have not yet introduced time subscripts to the labor market states above since the market is in a steady state. However, the transition rates vary by quarter, and so each quarter has a distinct steady state, denoted with the subscript $t$ that matches the subscript for the transition rates. The fourth equation is a linear combination of the first three equations, and thus one more equation is necessary to close the model. This final equation is that the stocks of $\left\{N_{t}^{*}, M_{t}^{*}, S_{t}^{*}, B_{t}^{*}\right\}$ sum to the population, where population counts are exogenously given:

$$
N_{t}^{*}+M_{t}^{*}+S_{t}^{*}+B_{t}^{*}=P_{t}
$$

After some algebra, a steady state solution for the 4-by-4 matrix is: 


$$
\begin{aligned}
& N_{t}^{*}=k_{t}\left(\left(\beta_{t} \lambda_{t}^{S B}+\lambda_{t}^{S M} \lambda_{t}^{S B}\right)\left(\beta_{t} \lambda_{t}^{B N}+\lambda_{t}^{B M} \lambda_{t}^{M N}\right)+\left(\beta_{t} \delta_{t}-\lambda_{t}^{B M} \lambda_{t}^{M B}\right)\left(\beta_{t} \lambda_{t}^{S N}+\lambda_{t}^{S M} \lambda_{t}^{M N}\right)\right) \\
& M_{t}^{*}=\left(\lambda_{t}^{N M} N_{t}^{*}+\lambda_{t}^{S M} S_{t}^{*}+\lambda_{t}^{B M} B_{t}^{*}\right) *\left(\beta_{t}\right)^{-1} \\
& S_{t}^{*}=\left(\left(\beta_{t} \alpha_{t}-\lambda_{t}^{N M} \lambda_{t}^{M N}\right) N_{t}^{*}+\left(\beta_{t} \lambda_{t}^{B N}+\lambda_{t}^{B M} \lambda_{t}^{M N}\right) B_{t}^{*}\right) *\left(\beta_{t} \lambda^{S N}+\lambda_{t}^{S M} \lambda_{t}^{M N}\right)^{-1}
\end{aligned}
$$

and

$$
B_{t}^{*}=k_{t}\left(\left(\beta_{t} \alpha_{t}-\lambda_{t}^{N M} \lambda_{t}^{M N}\right)\left(\beta_{t} \lambda_{t}^{S B}+\lambda_{t}^{S M} \lambda_{t}^{S B}\right)+\left(\beta_{t} \lambda_{t}^{N B}+\lambda_{t}^{N M} \lambda_{t}^{M B}\right)\left(\beta_{t} \lambda_{t}^{S N}+\lambda_{t}^{S M} \lambda_{t}^{M N}\right)\right)
$$

where

$$
\begin{aligned}
& \alpha_{t}=\left(\lambda_{t}^{N M}+\lambda_{t}^{N S}+\lambda_{t}^{N B}\right) \\
& \beta_{t}=\left(\lambda_{t}^{M N}+\lambda_{t}^{M S}+\lambda_{t}^{M B}\right)
\end{aligned}
$$

and

$$
\delta_{t}=\left(\lambda_{t}^{B N}+\lambda_{t}^{B M}+\lambda_{t}^{B S}\right)
$$

Finally, $k_{t}$ is a multiplier that recovers $N_{t}^{*}+M_{t}^{*}+S_{t}^{*}+B_{t}^{*}=P_{t}$. 
Figure 1: Hires, Separations, and Single Quarter Jobs

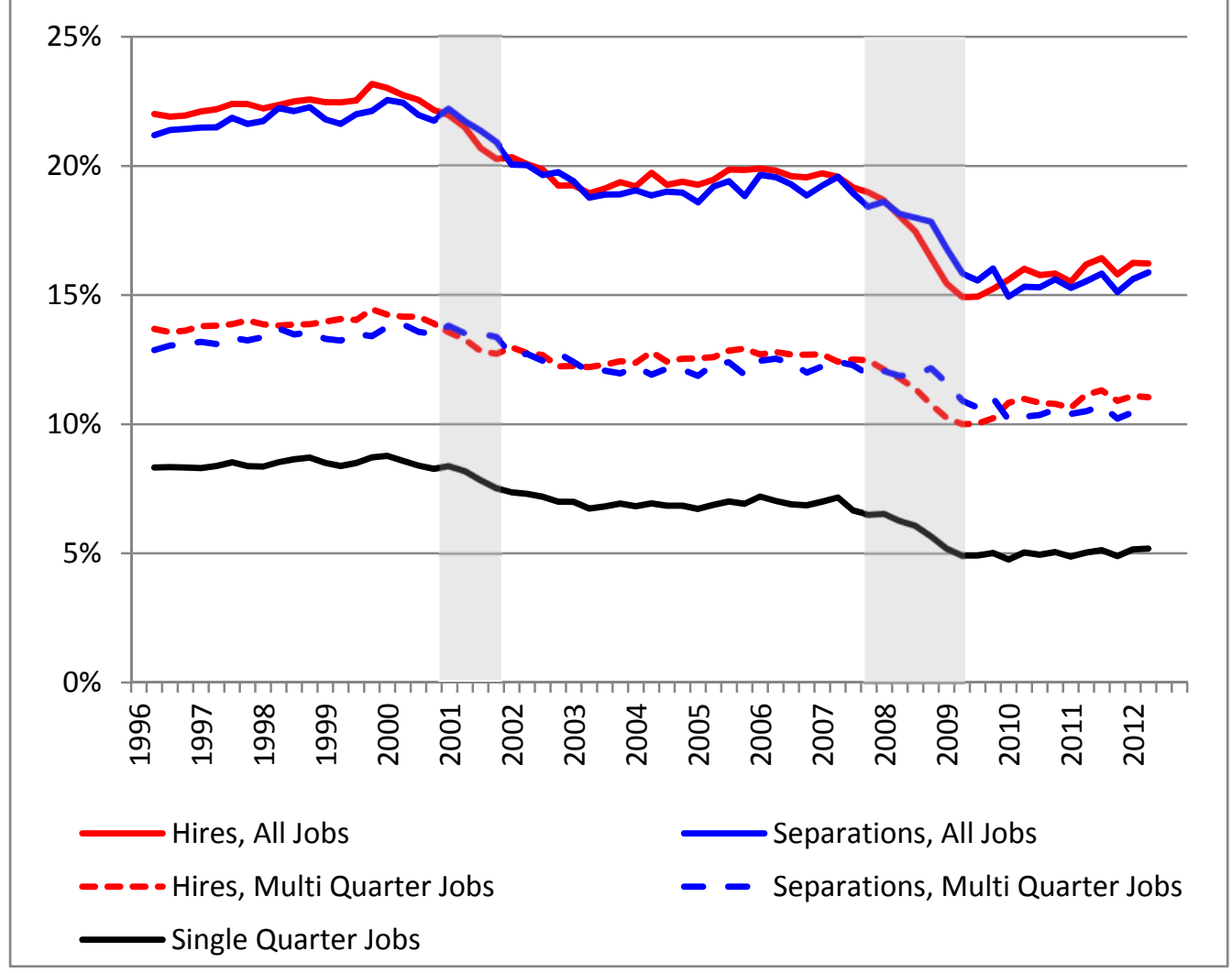

Note: Authors' tabulations of LEHD data from 20 states, 1996:Q2 - 2012:Q2, seasonally adjusted. 
Table 1a: Descriptive Statistics, by Worker Characteristics

\begin{tabular}{lccc}
\hline \hline & $\begin{array}{c}\text { Incidence of } \\
\text { Single Quarter } \\
\text { Jobs }\end{array}$ & $\begin{array}{c}\text { Percent of } \\
\text { Single Quarter } \\
\text { Jobs }\end{array}$ & $\begin{array}{c}\text { Percent of } \\
\text { All Jobs }\end{array}$ \\
\hline Age & & & \\
$14-18$ & $15.4 \%$ & $13.2 \%^{*}$ & $6.0 \%$ \\
$19-21$ & $13.1 \%$ & $13.3 \%^{*}$ & $7.1 \%$ \\
$22-24$ & $9.8 \%$ & $10.3 \%$ & $7.4 \%$ \\
$25-34$ & $7.1 \%$ & $23.7 \%$ & $23.4 \%$ \\
$35-44$ & $5.5 \%$ & $18.1 \%{ }^{*}$ & $23.2 \%$ \\
$45-54$ & $4.4 \%$ & $12.1 \%{ }^{*}$ & $19.4 \%$ \\
$55-64$ & $4.0 \%$ & $5.7 \%$ & $10.0 \%$ \\
$65-99$ & $7.5 \%$ & $3.7 \%$ & $3.5 \%$ \\
& & & \\
Gender & & & \\
Male & $7.3 \%$ & $55.3 \%$ & $53.0 \%$ \\
Female & $6.7 \%$ & $44.7 \%$ & $47.0 \%$ \\
& & & \\
Education & & & \\
Less than High School & $9.5 \%$ & $21.4 \%{ }^{*}$ & $15.7 \%$ \\
High School or Equivalent & $7.5 \%$ & $29.0 \%$ & $27.3 \%$ \\
Some College or Associate Degree & $6.7 \%$ & $30.0 \%$ & $31.4 \%$ \\
Bachelor's Degree or More & $5.4 \%$ & $19.6 \%{ }^{*}$ & $25.7 \%$ \\
\hline
\end{tabular}

Notes: Authors' tabulations of LEHD data from 20 states, 1996:Q2 - 2012:Q2. * indicates that the percent of single quarter jobs differs from the percent of all jobs by 5 percentage points or more. 


\begin{tabular}{|c|c|c|c|}
\hline & $\begin{array}{c}\text { Incidence of } \\
\text { Single Quarter } \\
\text { Jobs } \\
\end{array}$ & $\begin{array}{c}\text { Percent of } \\
\text { Single Quarter } \\
\text { Jobs } \\
\end{array}$ & $\begin{array}{c}\text { Percent of } \\
\text { All Jobs }\end{array}$ \\
\hline \multicolumn{4}{|l|}{ Firm Size } \\
\hline$<20$ & $8.0 \%$ & $24.1 \%$ & $21.2 \%$ \\
\hline $20-49$ & $7.5 \%$ & $11.3 \%$ & $10.6 \%$ \\
\hline $50-249$ & $7.3 \%$ & $17.2 \%$ & $16.5 \%$ \\
\hline $250-999$ & $7.5 \%$ & $11.4 \%$ & $10.7 \%$ \\
\hline$\geq 1000$ & $6.1 \%$ & $36.0 \%{ }^{*}$ & $41.1 \%$ \\
\hline \multicolumn{4}{|l|}{ Firm Age } \\
\hline 0-1 years & $11.9 \%$ & $10.2 \%$ & $6.0 \%$ \\
\hline $2-3$ years & $10.4 \%$ & $8.1 \%$ & $5.5 \%$ \\
\hline $4-5$ years & $9.5 \%$ & $6.8 \%$ & $5.0 \%$ \\
\hline $6-10$ years & $8.9 \%$ & $13.5 \%$ & $10.6 \%$ \\
\hline 11-19 years & $7.9 \%$ & $17.7 \%$ & $15.7 \%$ \\
\hline 20 or more years & $5.3 \%$ & $43.7 \%{ }^{*}$ & $57.2 \%$ \\
\hline \multicolumn{4}{|l|}{ Industry } \\
\hline Agriculture, Forestry, Fishing & $24.0 \%$ & $6.7 \%$ & $2.0 \%$ \\
\hline Mining & $4.8 \%$ & $0.4 \%$ & $0.6 \%$ \\
\hline Utilities & $1.8 \%$ & $0.1 \%$ & $0.5 \%$ \\
\hline Construction & $9.9 \%$ & $9.1 \%$ & $6.4 \%$ \\
\hline Manufacturing & $3.2 \%$ & $5.7 \%{ }^{*}$ & $12.6 \%$ \\
\hline Wholesale Trade & $3.4 \%$ & $2.5 \%$ & $5.1 \%$ \\
\hline Retail Trade & $6.4 \%$ & $12.8 \%$ & $14.0 \%$ \\
\hline Transportation \& Warehousing & $5.4 \%$ & $2.7 \%$ & $3.5 \%$ \\
\hline Information & $6.8 \%$ & $3.1 \%$ & $3.2 \%$ \\
\hline Finance and Insurance & $2.7 \%$ & $1.8 \%$ & $4.7 \%$ \\
\hline Real Estate \& Rental \& Leasing & $5.2 \%$ & $1.4 \%$ & $1.9 \%$ \\
\hline Professional, Sci, \& Tech Services & $4.9 \%$ & $4.5 \%$ & $6.4 \%$ \\
\hline Management of Companies & $2.8 \%$ & $0.4 \%$ & $1.1 \%$ \\
\hline Admin, Support, \& Waste & $17.0 \%$ & $20.5 \%{ }^{*}$ & $8.4 \%$ \\
\hline Educational Services & $6.1 \%$ & $1.5 \%$ & $1.7 \%$ \\
\hline Health Care \& Social Assistance & $3.9 \%$ & $6.5 \%{ }^{*}$ & $11.8 \%$ \\
\hline Arts, Entertainment, \& Recreation & $8.7 \%$ & $2.3 \%$ & $1.9 \%$ \\
\hline Accommodation \& Food Services & $10.0 \%$ & $14.6 \%$ & $10.2 \%$ \\
\hline Other Services (ex Public Admin) & $5.9 \%$ & $3.5 \%$ & $4.1 \%$ \\
\hline
\end{tabular}

Notes: Authors' tabulations of LEHD data from 20 states, 1996:Q2 - 2012:Q2. * indicates that the percent of single quarter jobs differs from the percent of all jobs by 5 percentage points or more. 
Table 2: Decomposition of the Declining

Incidence of Single Quarter Jobs

Composition

Effect

\begin{tabular}{lc}
\hline Worker Characteristics & $13.9 \%$ \\
Age & $0.0 \%$ \\
Gender & $-1.6 \%$ \\
Education & \\
& \\
Employer Characteristics & $-3.0 \%$ \\
Industry & $14.7 \%$ \\
Firm Age & $2.6 \%$ \\
Firm Size & \\
& $21.6 \%$ \\
All Characteristics & \\
\hline Notes: Authors' tabulations of LEHD data from 20 states, \\
1996:Q2 - 2012:Q2.
\end{tabular}


Figure 2: Incidence of Single Quarter Jobs, by Quarter

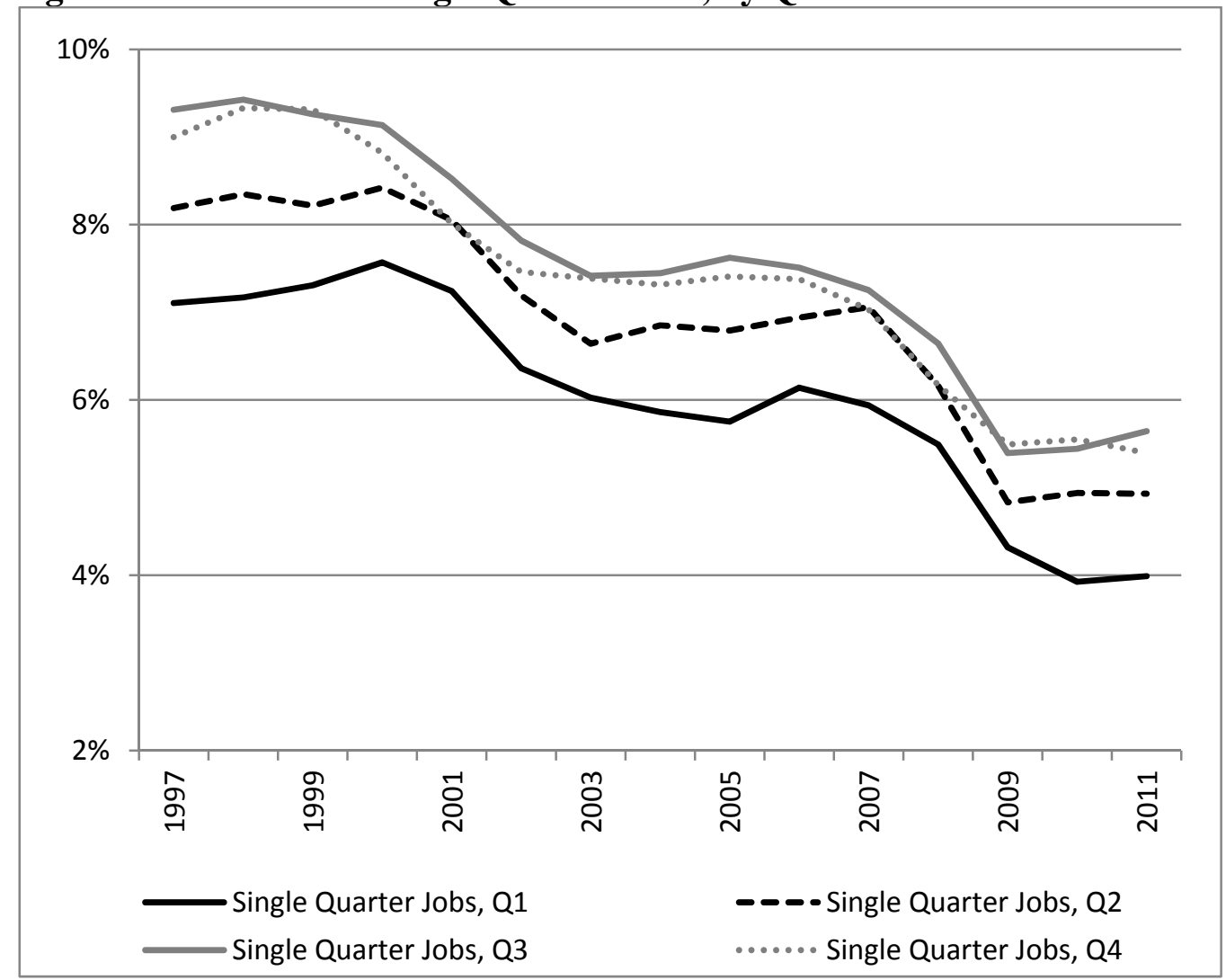

Notes: Authors' tabulations of LEHD data from 20 states, 1996:Q2 - 2012:Q2. 
Figure 3: Incidence of Single Quarter Jobs, Jobs-Based and Individual-Based

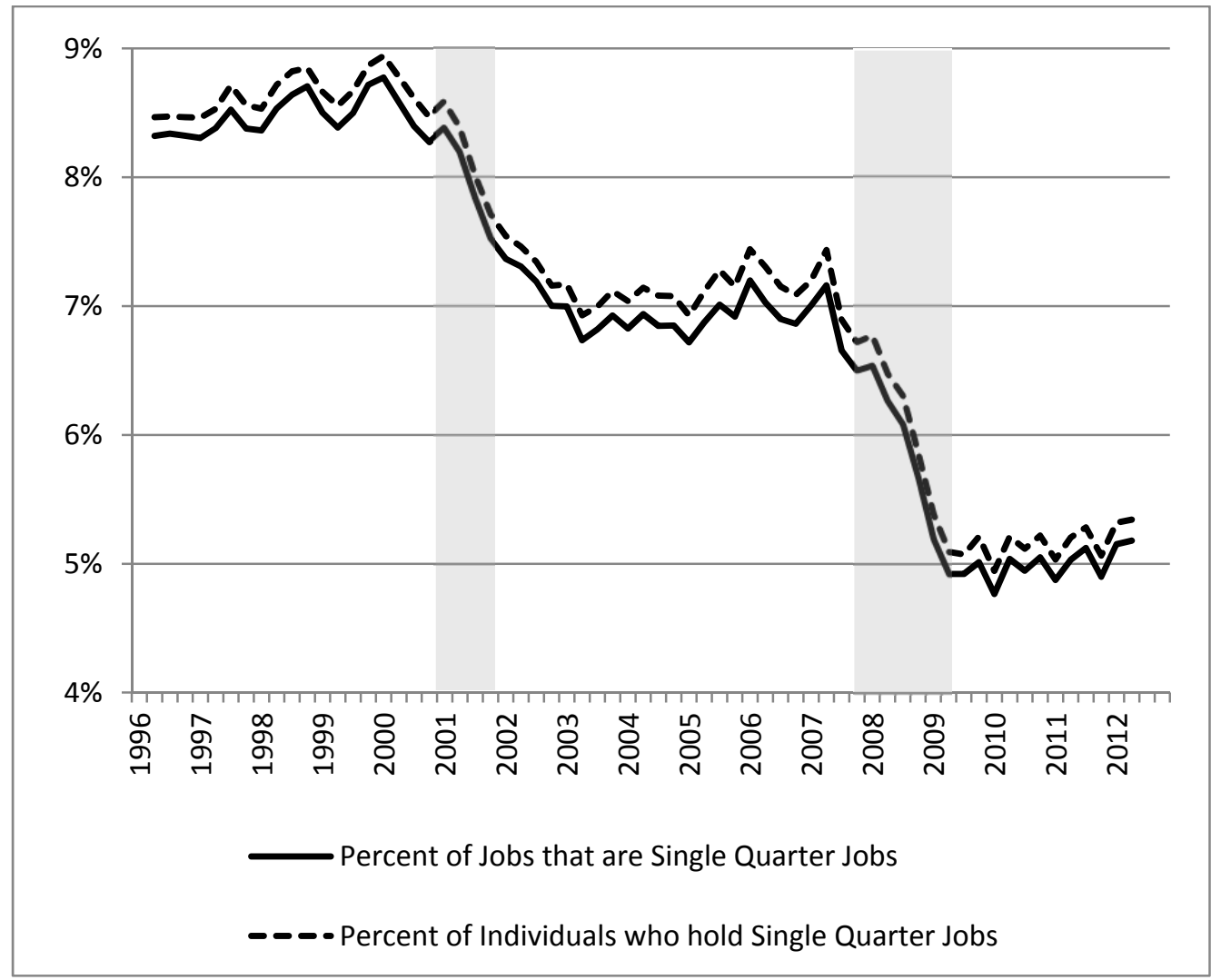

Notes: Authors' tabulations of LEHD data from 20 states, 1996:Q2 - 2012:Q2, seasonally adjusted. 
Figure 4: Incidence of Single Quarter Jobs, by Type

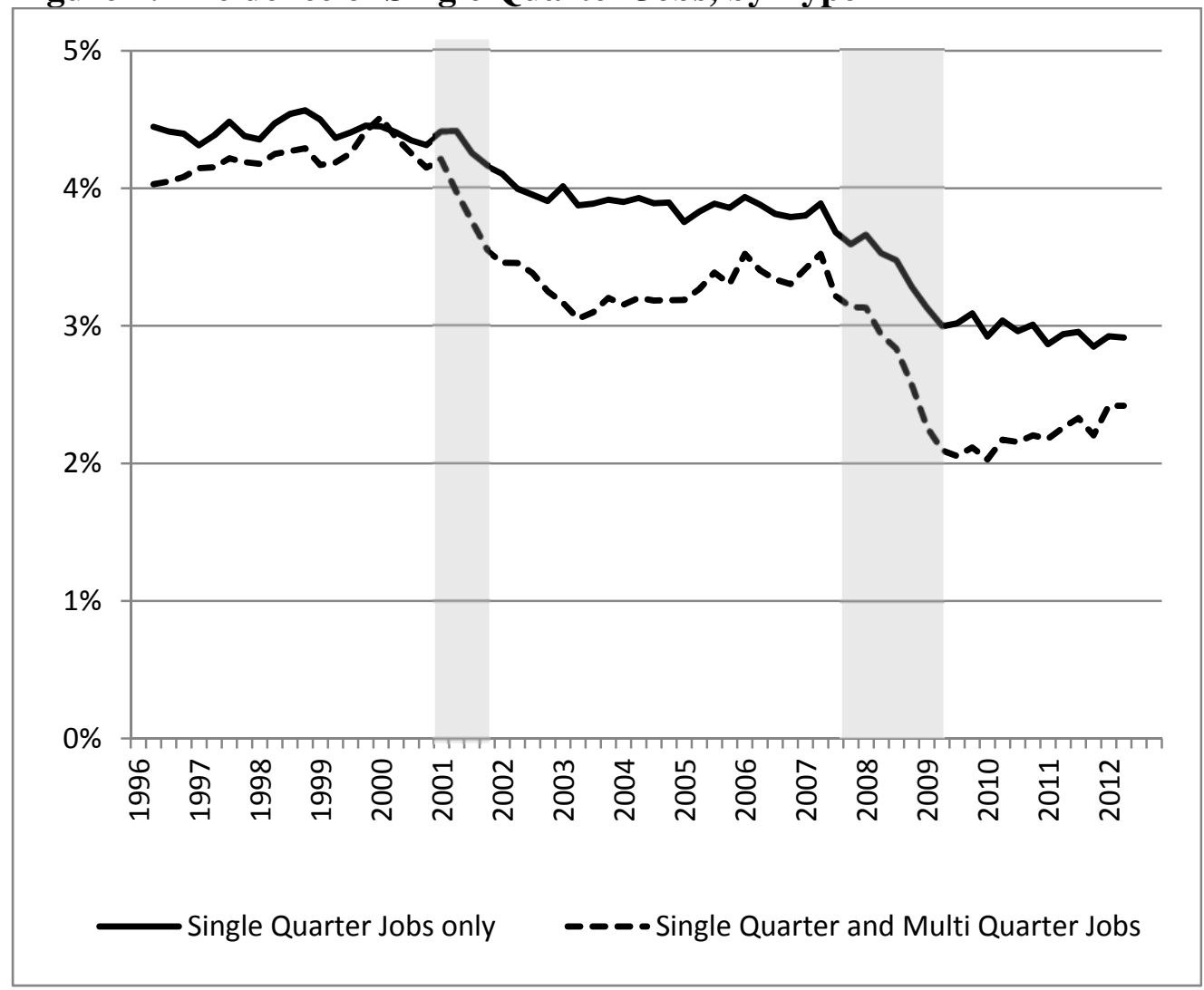

Notes: Authors' tabulations of LEHD data from 20 states, 1996:Q2 - 2012:Q2, seasonally adjusted. 
Figure 5: Incidence of Single Quarter and Multi Quarter Jobs (as a Percentage of the Population)

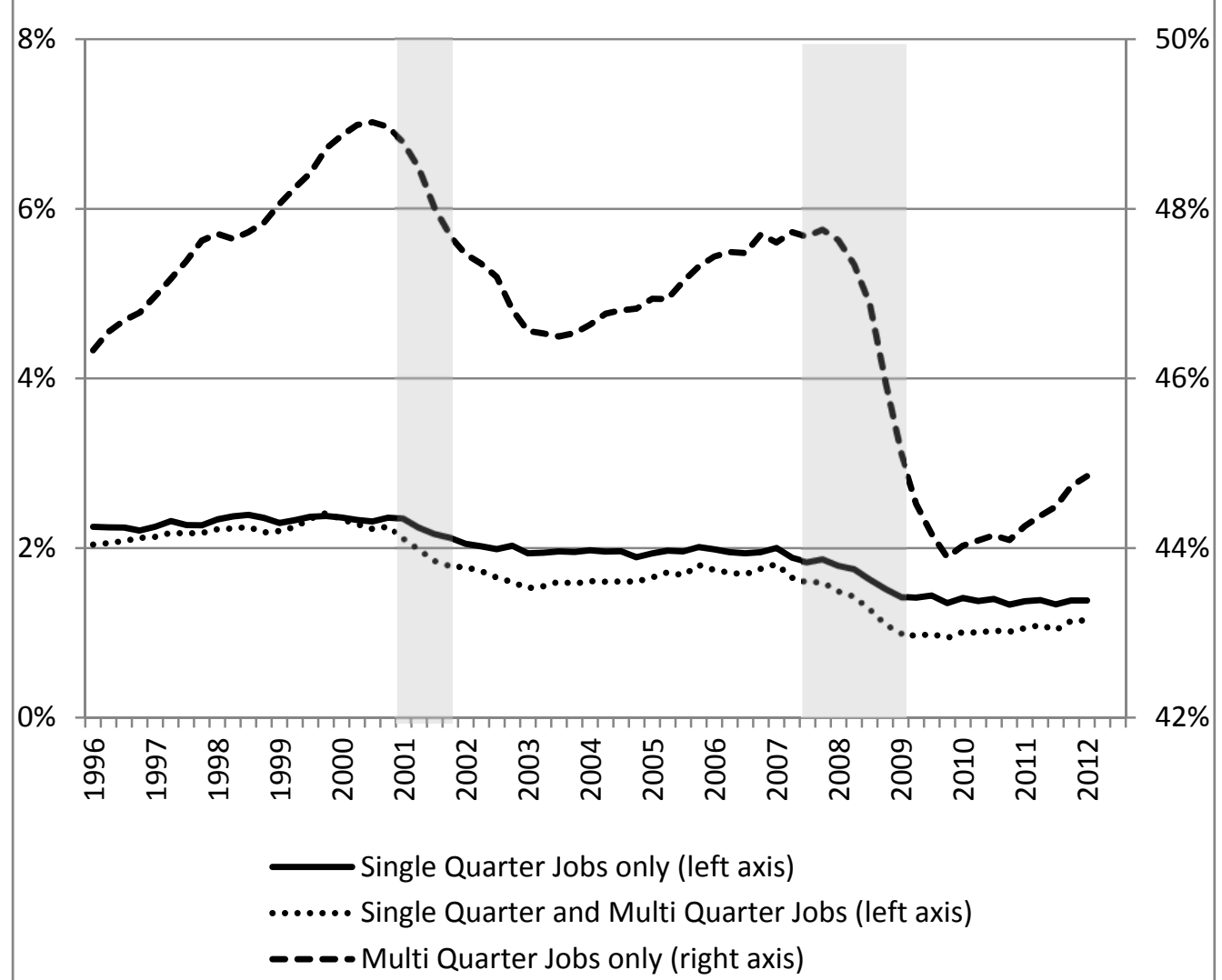

Notes: Authors' tabulations of LEHD data from 20 states, 1996:Q2 - 2012:Q2, seasonally adjusted. 
Table 3a: Transition Matrix (as Percentage of the Population)

\begin{tabular}{ccccccc}
\hline \hline & & \multicolumn{5}{c}{ Subsequent Quarter Labor Market State } \\
\cline { 3 - 7 } & & None & Multi & Single & Both & Any \\
\hline \multirow{2}{*}{ Previous } & None & $38.8 \%$ & $3.2 \%$ & $1.5 \%$ & $0.3 \%$ & $43.8 \%$ \\
Labor & Multi & $3.2 \%$ & $47.8 \%$ & $0.3 \%$ & $1.2 \%$ & $52.4 \%$ \\
Market & Single & $1.4 \%$ & $0.3 \%$ & $0.3 \%$ & $0.1 \%$ & $2.1 \%$ \\
State & Both & $0.2 \%$ & $1.3 \%$ & $0.1 \%$ & $0.2 \%$ & $1.7 \%$ \\
& Any & $43.6 \%$ & $52.6 \%$ & $2.1 \%$ & $1.7 \%$ & $100 \%$ \\
\hline
\end{tabular}

Notes: Authors' tabulations of LEHD data from 20 states, 1996:Q2 - 2012:Q2, seasonally adjusted. Data are restricted to individuals aged 18-65. "None" represents individuals with no single quarter jobs and no multi quarter jobs, "Multi" represents individuals with no single quarter jobs and one or more multi quarter jobs, "Single" represents individuals with one or more single quarter jobs and no multi quarter jobs, and "Both" represents individuals with one or more single quarter jobs and one or more multi quarter jobs.

Table 3b: Transition Probabilities (Conditional on Previous State)

\begin{tabular}{|c|c|c|c|c|c|c|}
\hline & & \multicolumn{5}{|c|}{ Subsequent Quarter Labor Market State } \\
\hline & & None & Multi & Single & Both & Any \\
\hline Previous & None & $88.6 \%$ & $7.4 \%$ & $3.4 \%$ & $0.6 \%$ & $100 \%$ \\
\hline Labor & Multi & $6.1 \%$ & $91.2 \%$ & $0.6 \%$ & $2.2 \%$ & $100 \%$ \\
\hline Market & Single & $69.0 \%$ & $15.2 \%$ & $12.3 \%$ & $3.4 \%$ & $100 \%$ \\
\hline State & Both & $11.6 \%$ & $72.2 \%$ & $3.6 \%$ & $12.6 \%$ & $100 \%$ \\
\hline
\end{tabular}

Notes: Authors' tabulations of LEHD data from 20 states, 1996:Q2 - 2012:Q2, seasonally adjusted. Data are restricted to individuals aged 18-65. "None" represents individuals with no single quarter jobs and no multi quarter jobs, "Multi" represents individuals with no single quarter jobs and one or more multi quarter jobs, "Single" represents individuals with one or more single quarter jobs and no multi quarter jobs, and "Both" represents individuals with one or more single quarter jobs and one or more multi quarter jobs. 
Table 4a: Transition Matrix for Young Adults (as a Percentage of the Population)

\begin{tabular}{ccccccc}
\hline \hline & & \multicolumn{5}{c}{ Subsequent Quarter Labor Market State } \\
\cline { 3 - 7 } & & None & Multi & Single & Both & Any \\
\hline \multirow{2}{*}{ Previous } & None & $30.7 \%$ & $6.7 \%$ & $2.9 \%$ & $0.7 \%$ & $40.9 \%$ \\
Labor & Multi & $6.8 \%$ & $41.8 \%$ & $0.6 \%$ & $2.2 \%$ & $51.4 \%$ \\
Market & Single & $2.8 \%$ & $0.7 \%$ & $0.6 \%$ & $0.2 \%$ & $4.3 \%$ \\
State & Both & $0.5 \%$ & $2.3 \%$ & $0.2 \%$ & $0.4 \%$ & $3.5 \%$ \\
& Any & $40.8 \%$ & $51.5 \%$ & $4.2 \%$ & $3.4 \%$ & $100 \%$ \\
\hline
\end{tabular}

Notes: Authors' tabulations of LEHD data from 20 states, 1996:Q2 - 2012:Q2, seasonally adjusted. Data are restricted to individuals aged 18-24. "None" represents individuals with no single quarter jobs and no multi quarter jobs, "Multi" represents individuals with no single quarter jobs and one or more multi quarter jobs, "Single" represents individuals with one or more single quarter jobs and no multi quarter jobs, and "Both" represents individuals with one or more single quarter jobs and one or more multi quarter jobs.

Table 4b: Transition Probabilities for Young Adults (Conditional on Previous State)

\begin{tabular}{ccccccc}
\hline \hline & & \multicolumn{5}{c}{ Subsequent Quarter Labor Market State } \\
\cline { 3 - 6 } & & None & Multi & Single & Both & Total \\
\hline Previous & None & $74.6 \%$ & $16.5 \%$ & $7.2 \%$ & $1.6 \%$ & $100 \%$ \\
Labor & Multi & $13.3 \%$ & $81.4 \%$ & $1.1 \%$ & $4.2 \%$ & $100 \%$ \\
Market & Single & $66.5 \%$ & $16.2 \%$ & $13.4 \%$ & $3.9 \%$ & $100 \%$ \\
State & Both & $15.8 \%$ & $67.9 \%$ & $4.3 \%$ & $12.0 \%$ & $100 \%$ \\
\hline
\end{tabular}

Notes: Authors' tabulations of LEHD data from 20 states, 1996:Q2 - 2012:Q2, seasonally adjusted. Data are restricted to individuals aged 18-24. "None" represents individuals with no single quarter jobs and no multi quarter jobs, "Multi" represents individuals with no single quarter jobs and one or more multi quarter jobs, "Single" represents individuals with one or more single quarter jobs and no multi quarter jobs, and "Both" represents individuals with one or more single quarter jobs and one or more multi quarter jobs. 
Figure 6: Observed and Steady State Labor Market States
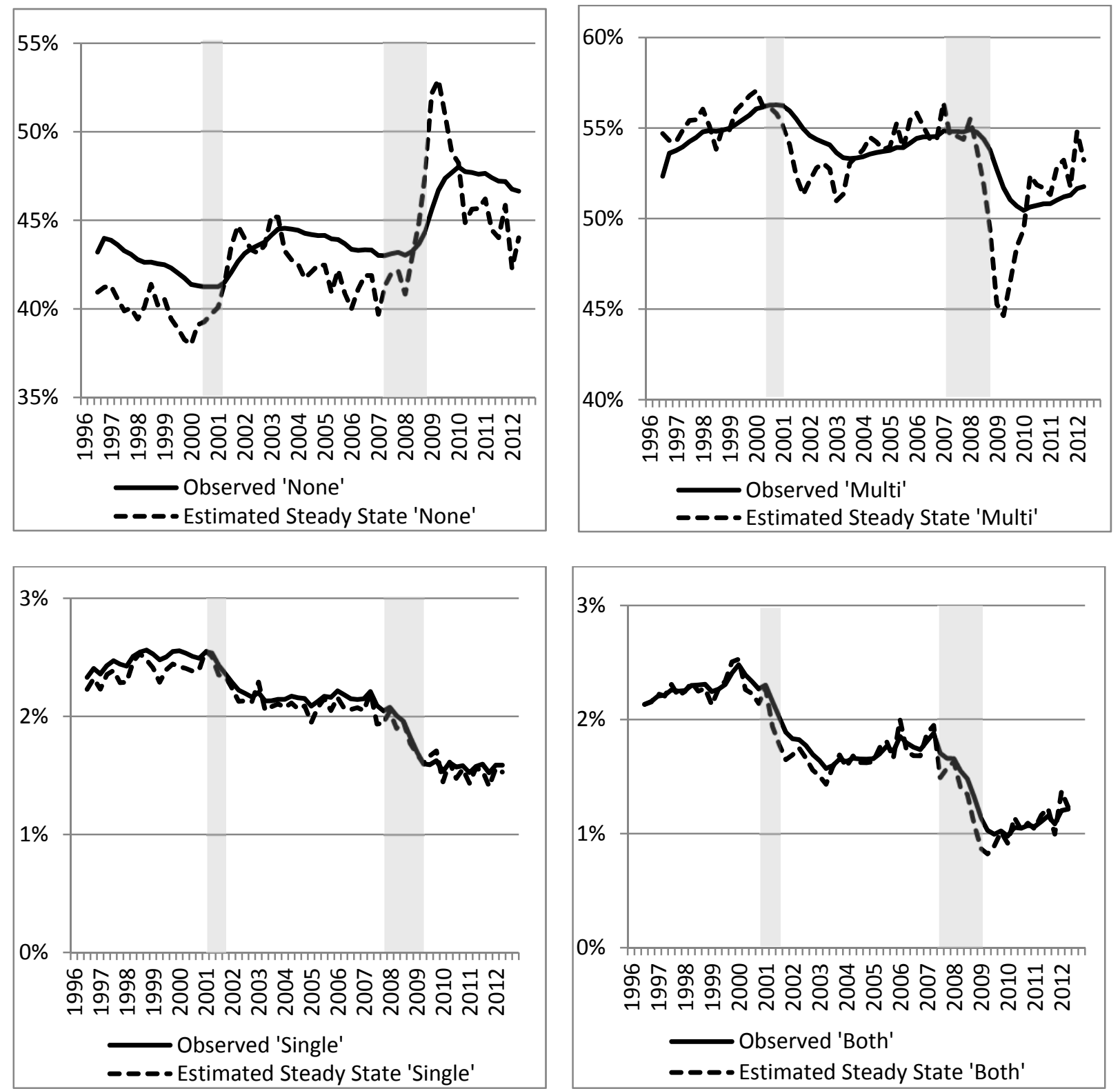

Notes: Authors' tabulations of LEHD data from 20 states, 1996:Q2 - 2012:Q2, seasonally adjusted. Data are restricted to individuals aged 18-65. "None" represents individuals with no single quarter jobs and no multi quarter jobs, "Multi" represents individuals with no single quarter jobs and one or more multi quarter jobs, "Single" represents individuals with one or more single quarter jobs and no multi quarter jobs, and "Both" represents individuals with one or more single quarter jobs and one or more multi quarter jobs. 
Table 5: Steady State Analysis of Transition Rates

\begin{tabular}{lcccc}
\hline \hline & $\begin{array}{c}\text { Movements in } \\
\text { "None" }\end{array}$ & $\begin{array}{c}\text { Movements in } \\
\text { "Multi" } \\
\text { explained by }\end{array}$ & $\begin{array}{c}\text { Movements in } \\
\text { "Single" } \\
\text { explained by }\end{array}$ & $\begin{array}{c}\text { Movements in } \\
\text { "Both" } \\
\text { explained by }\end{array}$ \\
\hline$\lambda^{\mathrm{NM}}$ & 1.039 & 1.209 & -.196 & .082 \\
$\lambda^{\mathrm{NS}}$ & .205 & .078 & .822 & .005 \\
$\lambda^{\mathrm{NB}}$ & .211 & .192 & -.033 & .209 \\
$\lambda^{\mathrm{MN}}$ & -.140 & -.180 & -.027 & .005 \\
$\lambda^{\mathrm{MS}}$ & -.120 & -.170 & .210 & -.007 \\
$\lambda^{\mathrm{MB}}$ & -.065 & -.225 & .041 & .619 \\
$\lambda^{\mathrm{SN}}$ & .030 & .012 & .122 & .002 \\
$\lambda^{\mathrm{SM}}$ & .038 & .053 & -.062 & .004 \\
$\lambda^{\mathrm{SB}}$ & -.004 & .003 & -.051 & .008 \\
$\lambda^{\mathrm{BN}}$ & .015 & .012 & -.003 & .023 \\
$\lambda^{\mathrm{BM}}$ & -.006 & -.019 & .005 & .084 \\
$\lambda^{\mathrm{BS}}$ & -.018 & -.021 & .029 & -.020 \\
\hline
\end{tabular}

Notes: Authors' tabulations of LEHD data from 20 states, 1996:Q2 - 2012:Q2, seasonally adjusted. Data are restricted to individuals aged 18-65. "None" represents individuals with no single quarter jobs and no multi quarter jobs, "Multi" represents individuals with no single quarter jobs and one or more multi quarter jobs, "Single" represents individuals with one or more single quarter jobs and no multi quarter jobs, and "Both" represents individuals with one or more single quarter jobs and one or more multi quarter jobs. $\lambda^{\bullet \bullet}$ are transition probabilities, where $\{\mathrm{N}, \mathrm{M}, \mathrm{S}, \mathrm{B}\}$ refer to $\{$ None, Multi, Single, Both\}. 
Figure 7: Number of Individuals, by Quarterly Employment Status

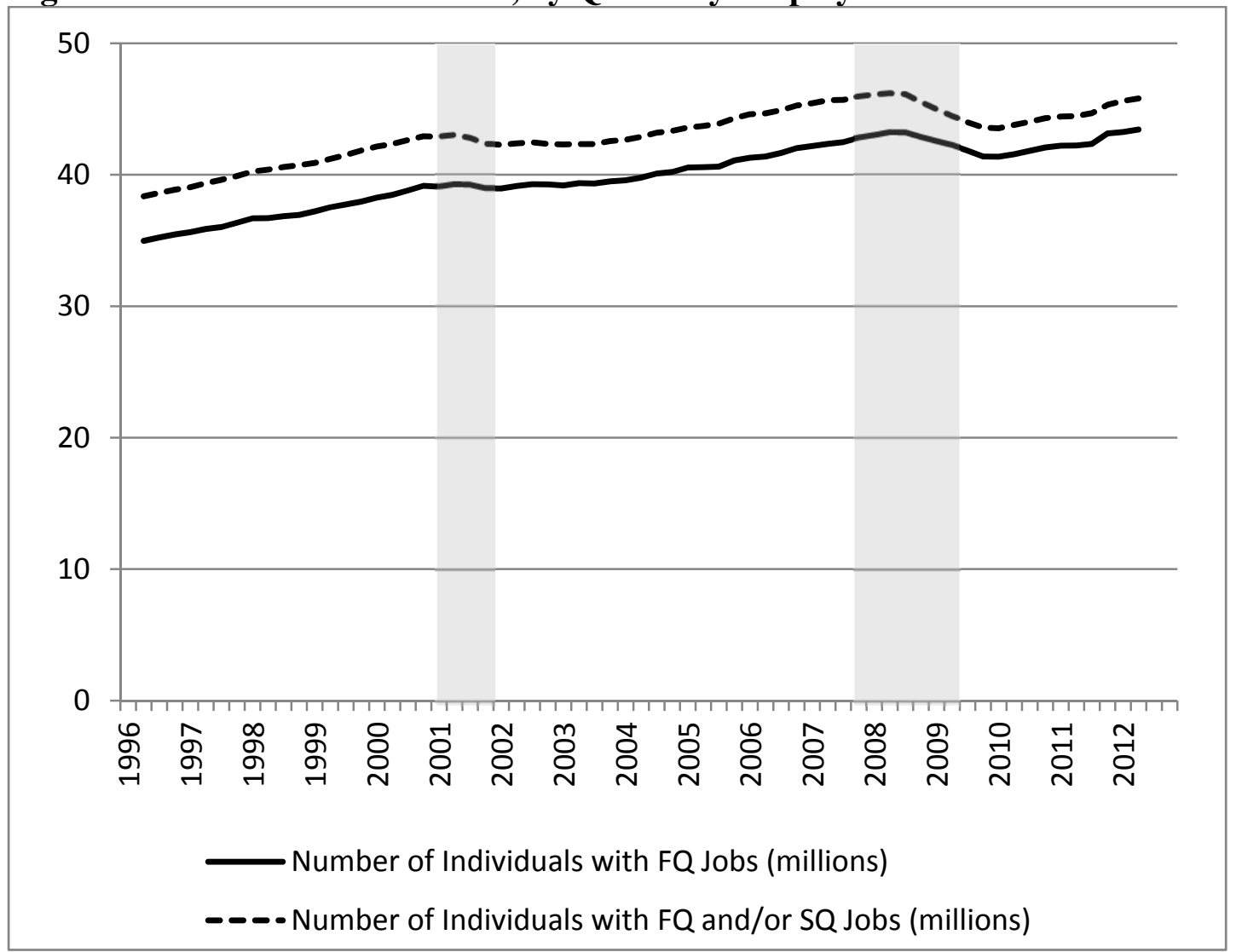

Notes: Authors' tabulations of LEHD data from 20 states, 1996:Q2 - 2012:Q2, seasonally adjusted. "FQ" refers to "Full Quarter" and "SQ" refers to "Single Quarter." 
Figure 8: Mean of Ln(Real Quarterly Earnings)

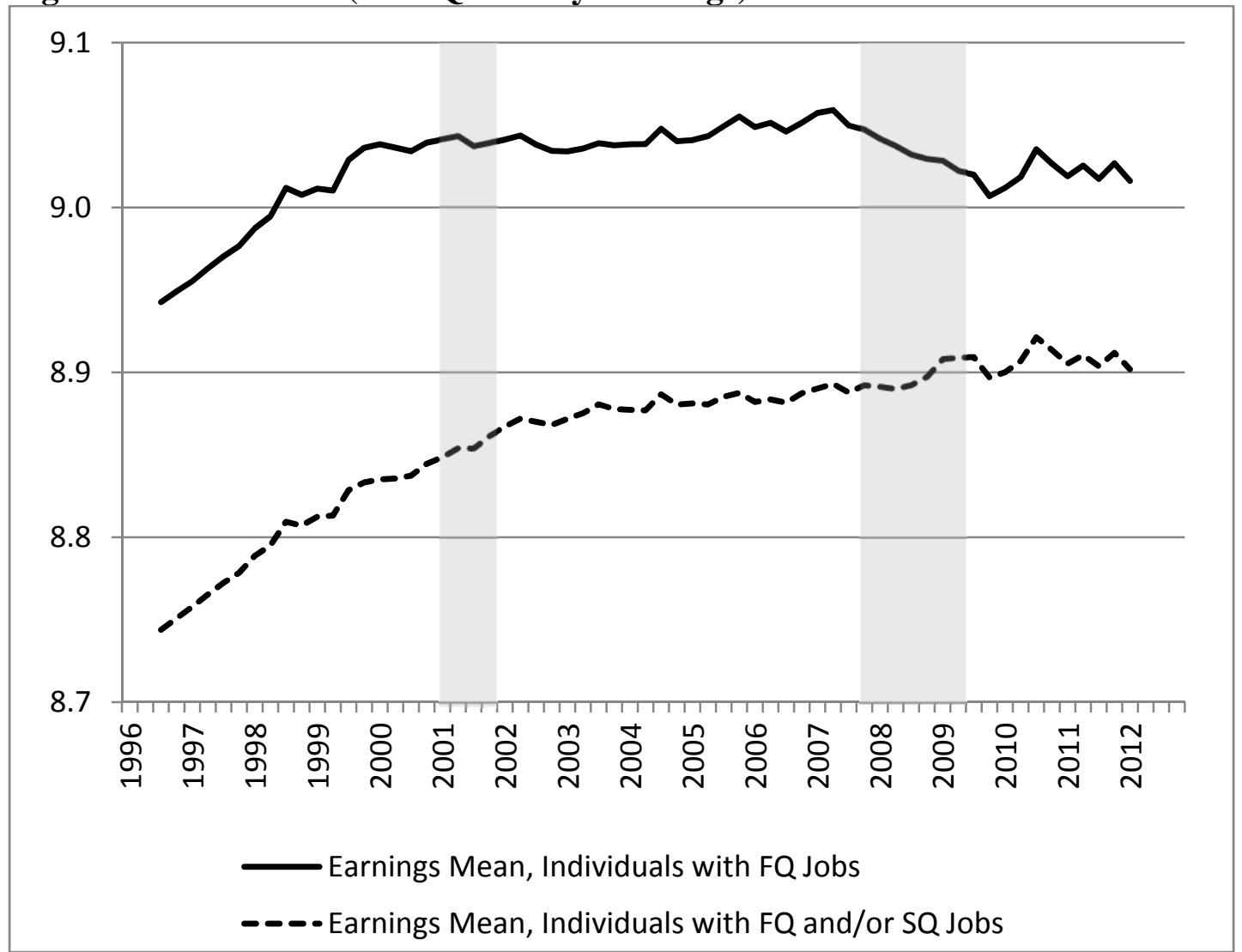

Notes: Authors' tabulations of LEHD data from 20 states, 1996:Q2 - 2012:Q2, seasonally adjusted. Both series are 3 quarter moving averages. "FQ" refers to "Full Quarter" and "SQ" refers to "Single Quarter.” 
Figure 9: Variance of Ln(Real Quarterly Earnings)

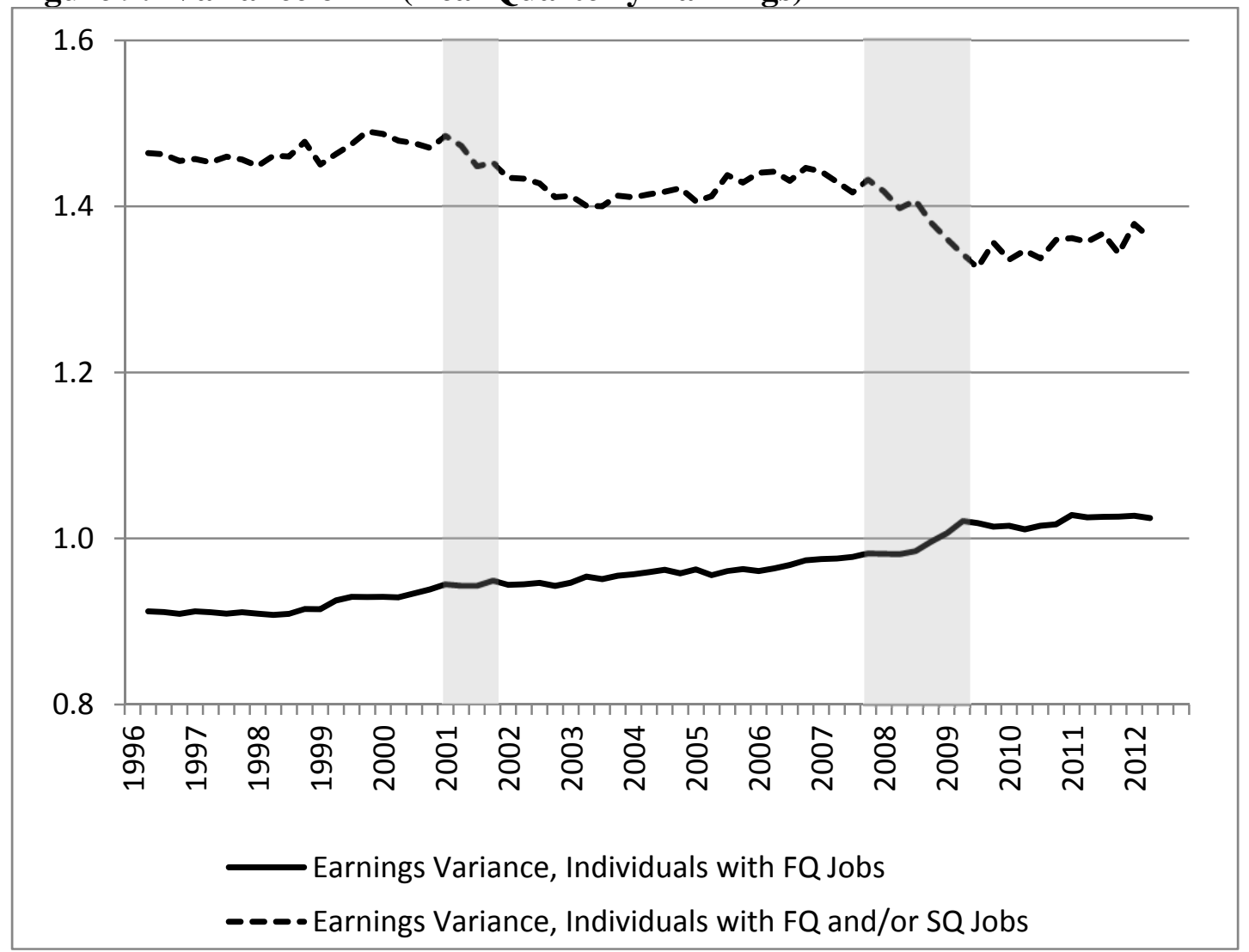

Notes: Authors' tabulations of LEHD data from 20 states, 1996:Q2 - 2012:Q2, seasonally adjusted. "FQ" refers to "Full Quarter" and "SQ" refers to "Single Quarter." 
Figure 10: Percentiles of the Earnings Distribution
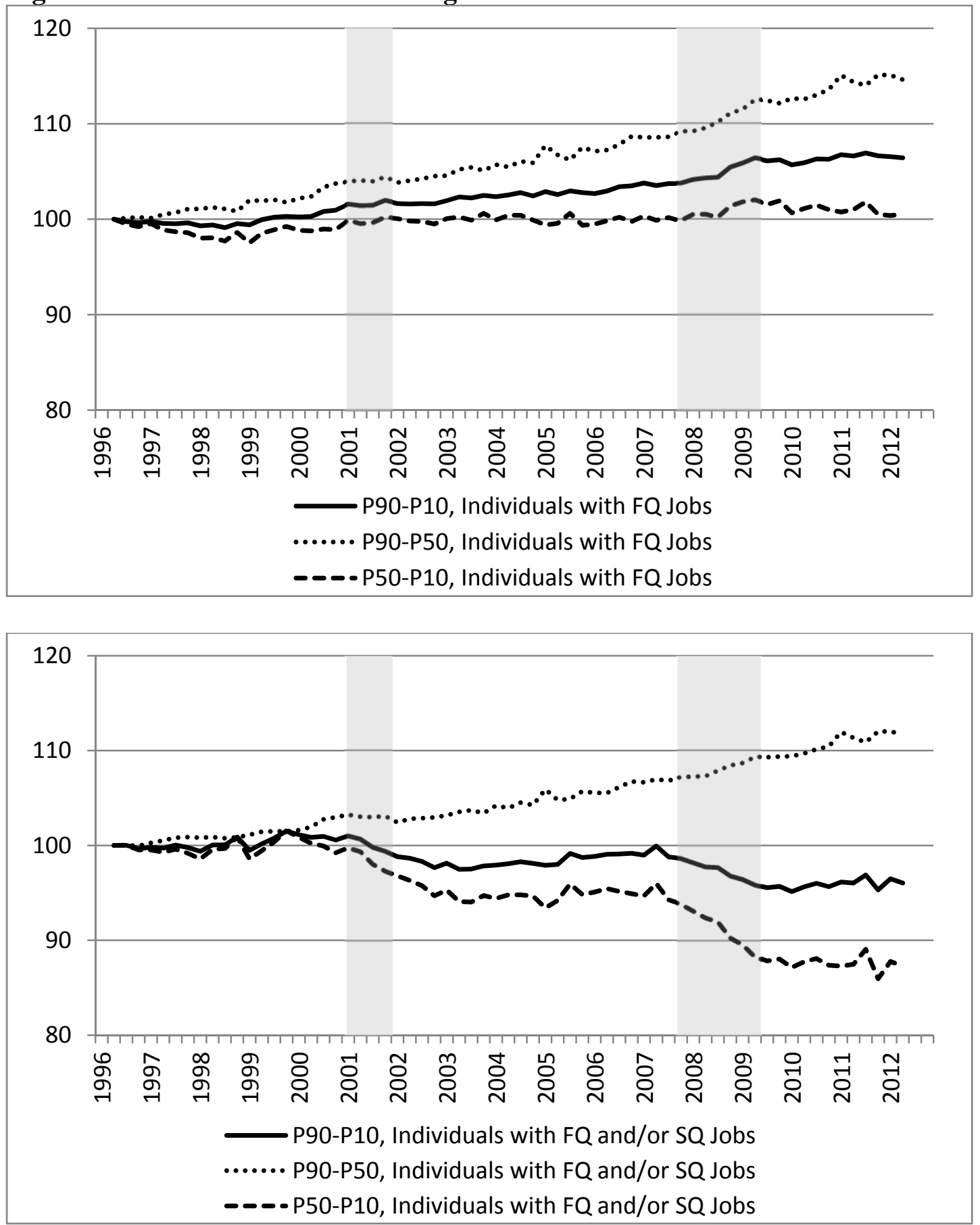

Notes: Authors' tabulations of LEHD data from 20 states, 1996:Q2 - 2012:Q2, seasonally adjusted. "FQ" refers to "Full Quarter" and "SQ" refers to "Single Quarter." 